\section{Check for updates}

Cite this: RSC Adv., 2019, 9, 36386

\title{
DABCO bond cleavage for the synthesis of piperazine derivatives $\dagger$
}

\begin{abstract}
Azim Ziyaei Halimehjani (iD * and Elham Badali
The applications of DABCO (1,4-diazabicyclo[2.2.2]octane) in the synthesis of piperazine derivatives including biologically active compounds via $\mathrm{C}-\mathrm{N}$ bond cleavage are investigated in this review. Different reagents such as alkyl halides, aryl(heteroary) halides, carboxylic acids, diaryliodonium salts, tosyl halides, activated alkynes, benzynes etc. were applied for the preparation of the corresponding quaternary ammonium salts of DABCO, which are very good electrophiles for various nucleophiles such as phenols, thiophenols, thiols, alcohols, aliphatic and aromatic amines, sulfinates, phthalimide, indoles, $\mathrm{NaN}_{3}$, triazole and terazoles, $\mathrm{NaCN}$, enols and enolates, halides, carboxylic acid salts etc. Besides preactivated DABCO salts, the in situ activation of DABCO in multicomponent reactions is also an efficient tactic in synthetic organic chemistry for the diversity oriented synthesis of drug-like piperazine derivatives.
\end{abstract}

Received 27th September 2019 Accepted 30th October 2019

DOI: $10.1039 / \mathrm{c} 9 \mathrm{ra0} 7870 \mathrm{c}$

rsc.li/rsc-advances

\section{Introduction}

Faculty of Chemistry, Kharazmi University, 49 Mofateh St., 15719-14911, Tehran, Iran.E-mail: ziyaei@khu.ac.ir

$\dagger$ Dedication to Prof. Jürgen Martens on the occasion of his 72nd birthday.

Heterocyclic rings show rich chemistry with a wide range of applications in a variety of fields such as organic and medicinal

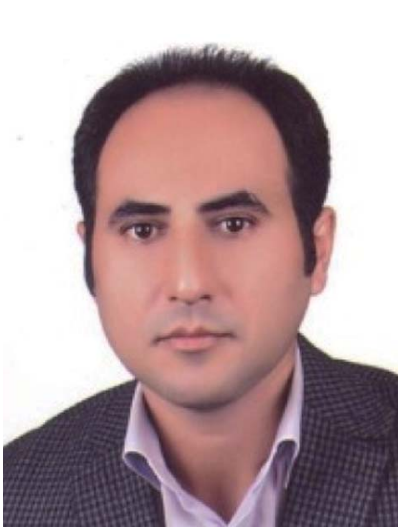

Azim Ziyaei Halimehjani was born in 1979 at Halimehjan, a small village in the Roudbar of Guilan, north of Iran. He obtained his BSc in pure chemistry in 2001 from Shiraz University. After completing his MSc in Organic Chemistry from Sharif University of Technology in 2003 under the supervision of Prof. $M$. R. Saidi and M. Tafazzoli, immediately he started his PhD under the supervision of Prof. $M$.

R. Saidi and advisor of Prof. J. Ipaktschi in the same University. During his $P h D$, he had two research visits from the research group of Prof. Ipaktschi (2005) and Prof. Peter R. Schreiner (2006) at Justus-Liebig-Universitat Giessen, Germany. After completing the PhD in 2007, he began his academic career as Assistant Prof. of Organic Chemistry at Kharazmi University, Tehran, Iran. In 2014, he promoted to Associate Prof. of Organic Chemistry in the same university. He has three research visits from research groups of Prof. Jürgen Martens (Oldenburg, 2015), Dr Petr Beier (IOCB Prague, 2017), and Prof. Bernhard Breit (Freiburg, 2018). He has published over 70 publications. He works in the area of synthetic organic chemistry and coordination chemistry with emphasis on the chemistry of dithiocarbamates, nitroalkenes, and development of new synthetic methodologies as well as green chemistry.

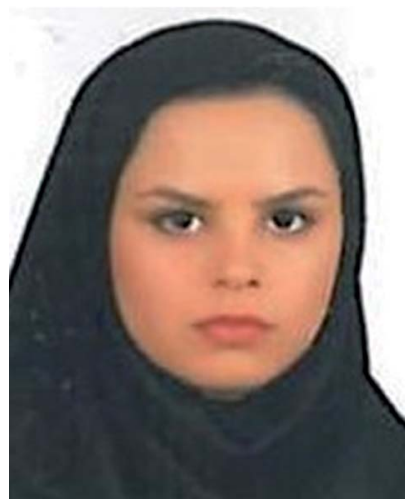

Elham Badali was born in Karaj, Alborz, Iran, in 1990. She received her BSc in pure chemistry in 2013 from Kharazmi University, Tehran, Iran, and her MSc in organic chemistry from Shahid Beheshti University, Tehran, Iran, under supervision of Prof. Ahmad Shaabani, in 2017. Now, she is working as a PhD student under supervision of $\mathrm{Dr}$ Azizolah Habibi and $\mathrm{Dr}$ Azim Ziyaei Halimehjani at Kharazmi University, Tehran, Iran. Her research interests include synthesis of novel intermediate for organic transformation and providing efficient catalyst for organic transformations. 
chemistry, pharmaceutical chemistry and industry. ${ }^{1}$ A great variety of heterocyclic compounds are presented in the structure of several drugs and renewable resources. ${ }^{2}$ Approximately half of the top 25 best-selling pharmaceuticals from the year 2014 contain nitrogen heterocyclic scaffolds with more than 50 billion USD in annual revenue. ${ }^{3}$ In addition, FDA databases reveal that nearly $60 \%$ of unique small-molecule drugs contain a nitrogen heterocycle. ${ }^{4}$ Among various nitrogen containing heterocyles, piperazine is very important building block in the structure of many compounds with widespread applications in different fields such as material, agrochemical, and medicinal chemistry. Piperazine is essential core in drug design and statistical substructure analysis revealed that it is the third most commonly used N-heterocycle (ranked after piperidine and pyridine) in small-molecule pharmaceuticals. ${ }^{5}$ Currently MDDR (MDL@Drug Data Report) database contains over 11800 structures bearing the piperazine moiety. These compounds have shown various biological activities such as anti-fungal, ${ }^{6}$ anti-depressant, ${ }^{7}$ anti-malarial, ${ }^{8}$ anti-migraine, ${ }^{9}$ anti-diabetic, ${ }^{10}$ anti-aggregating, ${ }^{11}$ anti-tumor, ${ }^{12}$ anti-inflammatory, ${ }^{13}$ antiobesity, ${ }^{14}$ and cardiovascular ${ }^{15}$ activities. The structure of some of the marketed drugs or drug candidates containing piperazine motif is shown in Fig. 1. Some of them such as Imatinib, Aripiprazole, Eszopiclone, Sitagliptin, Quetiapine and Sildenafil are within the top 100 best-selling drugs. ${ }^{4}$ In most of these compounds, piperazine scaffold is mainly used as a linker between two portions of a drug or as mediator for tuning the physicochemical properties of drugs. Similarly, most of the piperazines isolated from natural products are unsubstituted at any of their carbon atoms. Besides biological activities, piperazine derivatives have found widespread applications in liquid crystals, ${ }^{16}$ metal-organic frameworks, ${ }^{17}$ coordination chemistry, ${ }^{18}$ coating, adhesives and sealing materials, ${ }^{19}$ selfassembled monolayer in electronic devices, ${ }^{20}$ novel chargetransfer polymers in solar cells, ${ }^{21}$ antistatic agents and vulcanization accelerators. ${ }^{22}$

The biological and industrial importance of piperazine derivatives encouraged chemists to find general and efficient approaches for the synthesis of these compounds. Various methods are available for the synthesis of piperazine derivatives in literature, most of them rely on cyclisation procedure. Novel synthetic approaches toward piperazine ring can be divided to the following main categories: (1) reduction of (di)ketopiperazine (di)ketopiperazine are generally synthesized from the amino acids or 1,2-diamines and other readily available starting materials, (2) $N$-alkylation of diamines with electrophiles including $\alpha$-halocarbonyl compounds, vinyl sulfonium salts, vinyl selenones, and etc., (3) catalytic or chemical reduction of pyrazines, pyrazinium salts, and pyrazine- $N$-oxides, (4) cyclocondensation of amines with alcohols via borrowing hydrogen<smiles></smiles><smiles>O=C1CCc2ccc(OCCCCN3CCN(c4cccc(Cl)c4Cl)CC3)cc21</smiles>

Aripiprazole

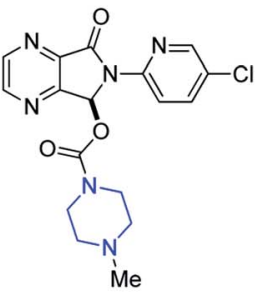

Eszopiclone

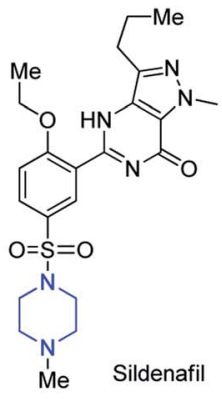<smiles>Cc1nc(Nc2ncc(C(=O)Nc3c(Cl)cccc3Cl)s2)cc(N2CCN(CCO)CC2)n1</smiles><smiles>CC(C)CCN1C=Nc2c(n(C)c(=O)n(C)c2=O)N1CCN1CCN(c2ccccc2I)CC1</smiles><smiles>C/C=C(/C)N1CCN(CCO)CC1</smiles><smiles>N[C@@H](CC(=O)N1CCn2c(nnc2C(F)(F)F)C1)Cc1cc(F)c(F)cc1F</smiles>
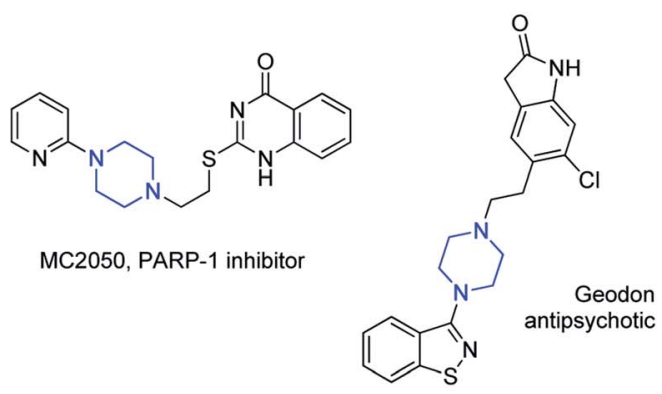

Fig. 1 Selected marketed drugs or drug candidates containing piperazine motif. 


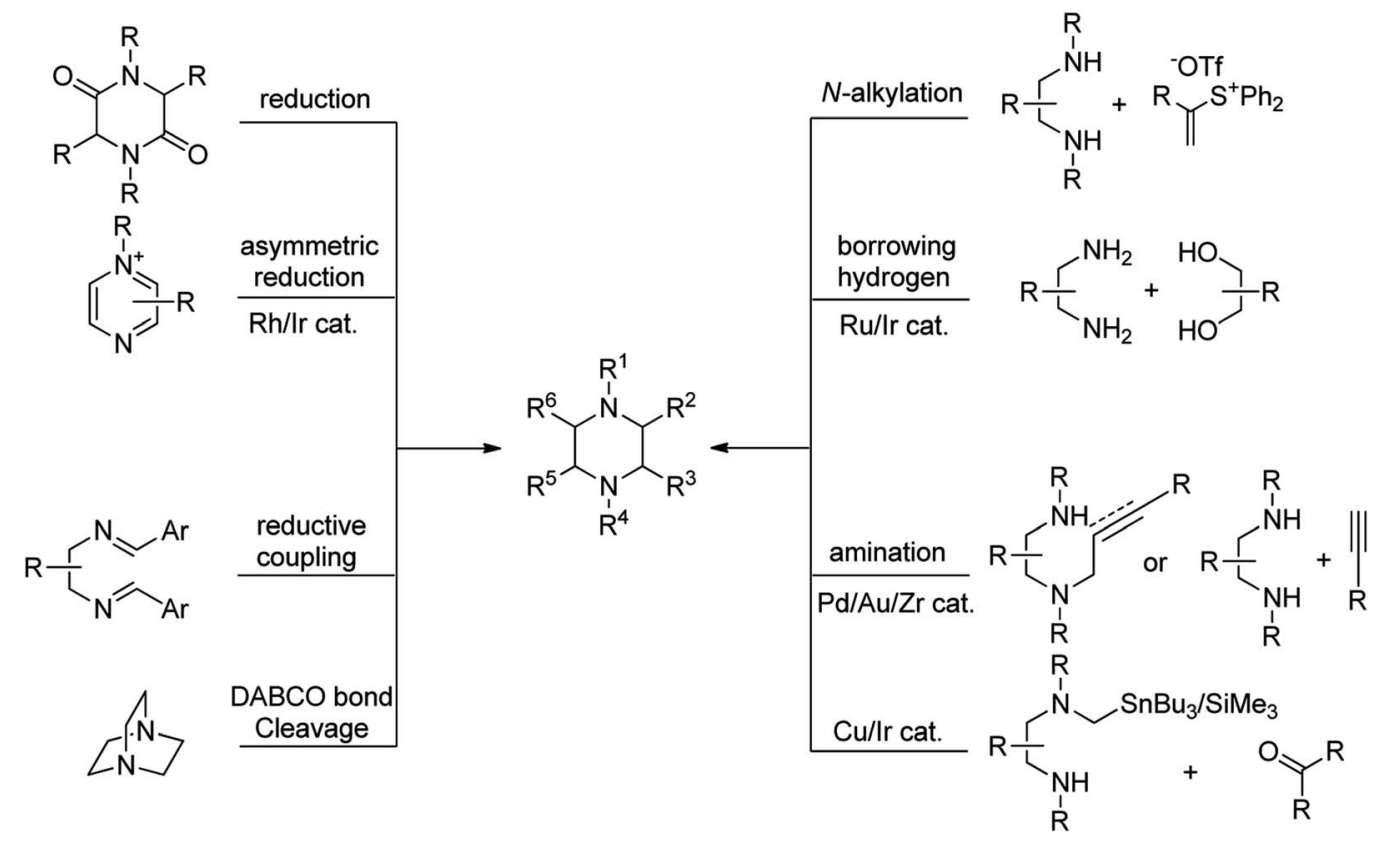

Fig. 2 General synthetic strategies toward piperazine scaffold.

strategy, (5) intramolecular reductive coupling of 1,2-diimines, (6) intermolecular or intramolecular amination of alkenes or alkynes, (7) DABCO bond cleavage, and (8) transition-metalcatalyzed condensation of stannyl (silicon) amine reagents with carbonyl compounds (Fig. 2). Other methods such as dimerization of aziridines [4+2]-cycloaddition of 1,2-diamines with allenes and alkynes, post-Ugi reaction, rearrangement of spiro compounds, and $\mathrm{C}-\mathrm{H}$ functionalization of piperazine ring are also well investigated in recent years..$^{23}$ Among the reported methods, DABCO bond cleavage is one of the most efficient and simple approaches for the synthesis of functionalized piperazines without affecting the carbons of piperazine ring. While most of the marketed or drug candidates contain simple piperazine ring in their structure, this strategy can be further utilized for the development of novel biologically active compounds in future.

According to the best of our knowledge, a review covering the synthesis of piperazine derivatives via DABCO bond cleavage is not available in the literature. For this purpose, this review serves as a comprehensive overview of published papers in the time range between 1962 until today for the synthesis of functionalized piperazine derivatives via DABCO bond cleavage. While preparation of DABCO based quaternary salts (Fig. 3) is the key step for the activation of $\mathrm{C}-\mathrm{N}$ bond in DABCO for cleavage, in this review paper, the papers are categorized<smiles>[R][N+]12CCN(CC1)CC2</smiles>

$\mathrm{R}=\mathrm{alkyl}$, aryl, heteroaryl, acyl, sulfonyl, vinyl and etc

Fig. 3 DABCO-quaternary salts. according to the type of activating agents such as alkyl halides, aryl(heteroaryl) halides, carboxylic acids, diaryliodonium salts, tosyl halides, activated alkynes, benzynes and etc.

\section{Alkyl halides as activating agents}

The first report on DABCO bond cleavage is came back to 1962 by $\mathrm{H}$. K. Hall. ${ }^{24} \mathrm{He}$ showed that by heating 1,4-diazabicyclo [2.2.2] octane 1 at $200{ }^{\circ} \mathrm{C}$ for $10.7 \mathrm{~h}$ in the presence of a catalytic amount of benzenesulfonic acid, the corresponding poly-1,4ethylenepiperazine 3 can be obtained in $96 \%$ yield. He concluded that the reaction proceeded via nucleophilic attack of the nitrogen of one DABCO on the protonated 2 or alkylated 3 form of another (Scheme 1).

In 1982, Vysochin and Shishkin ${ }^{25}$ reported the reaction of 2or/and 3-substituted DABCO derivatives 5 with methylating agents such as methyl iodide, methyl benzoates and dimethyl sulfate for the preparation of the corresponding mono- or bisquaternary salts 6 and 7. The monoquaternary salts 6 can be converted to the corresponding piperazine derivatives by reacting with a nucleophile such as sodium benzoate at 130$140{ }^{\circ} \mathrm{C}$. The bisquaternary salts 7 were converted to the corresponding monoquaternary salts 6 prior to DABCO bond cleavage with nucleophile to provide the piperazine derivatives 8 (Scheme 2).

Recently, Kocevar et al. ${ }^{26}$ have investigated the reaction of quaternary salts of DABCO 9 with phenols and related nucleophiles to prepare 1-alkyl-4-(2-phenoxyethyl) piperazines and related derivatives 10. The reactions were performed in polyethyleneglycol (PEG) or diglyme at high temperatures. Various nucleophiles such as phenols, thiophenols, potassium phthalimide, sodium methoxide, and benzothiazole-2-thioate were applied in DABCO ring opening reactions to give moderate to 


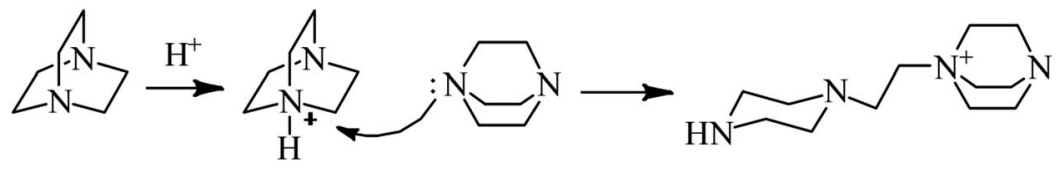

1

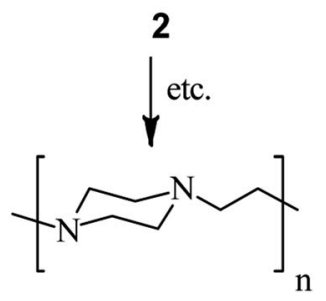

3

Scheme 1 Synthesis of poly-1,4-ethylenepiperazine from DABCO

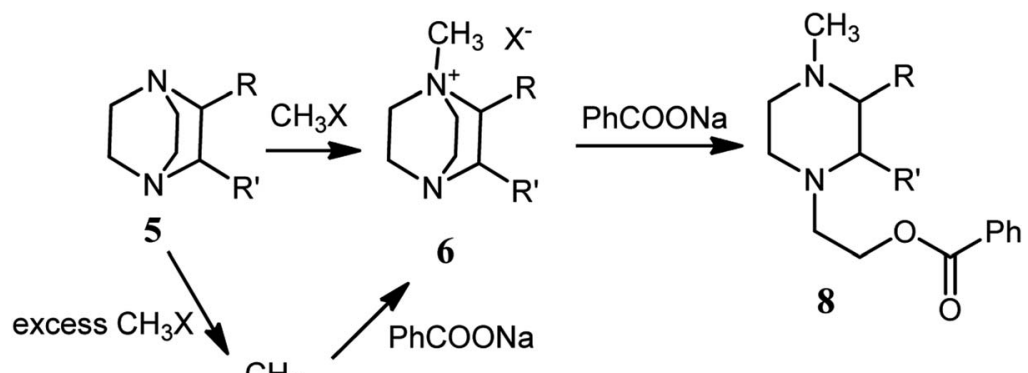<smiles>[R]C1C([R])[N+]2(C)CC[N+]1(C)CC2</smiles>

$\mathrm{X}^{-}=\mathrm{Cl}^{-}, \mathrm{Br}^{-}, \mathrm{I}^{-}$, and $\mathrm{CH}_{3} \mathrm{SO}_{4}^{-}$

7

Scheme 2 Synthesis of mono- or bisquaternary salts of DABCO and their ring opening with sodium benzoate.
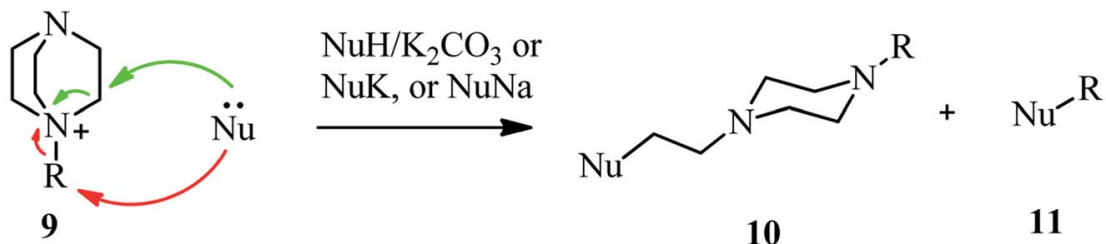

NuH: Phenol, naphthol and their derivatives,

Thiophenol, 2-mercaptobenzothiazole, $\mathrm{NaBH}_{4}$,

$\mathrm{NaOMe}$, potasium Phthalimide

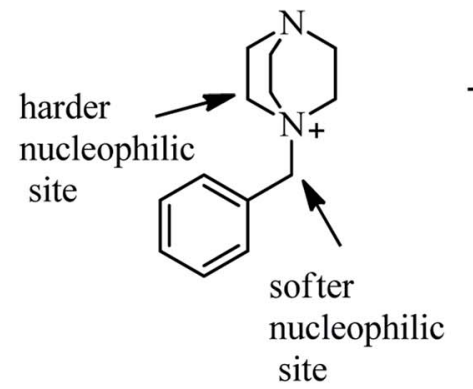

\begin{tabular}{lc} 
Nucleophile & Benzylation/Ring-opening ratio \\
\hline Methanolate & 0.00 \\
Phthalimide & 0.22 \\
Phenolate & 0.41 \\
Tetrahydroborate & 0.61 \\
Benzenethiolate & 0.75 \\
Benzothiazole-2-thiolate & 1.00
\end{tabular}

Scheme $3 \mathrm{C}-\mathrm{N}$ bond cleavage of DABCO quaternary salts with various nucleophiles. 


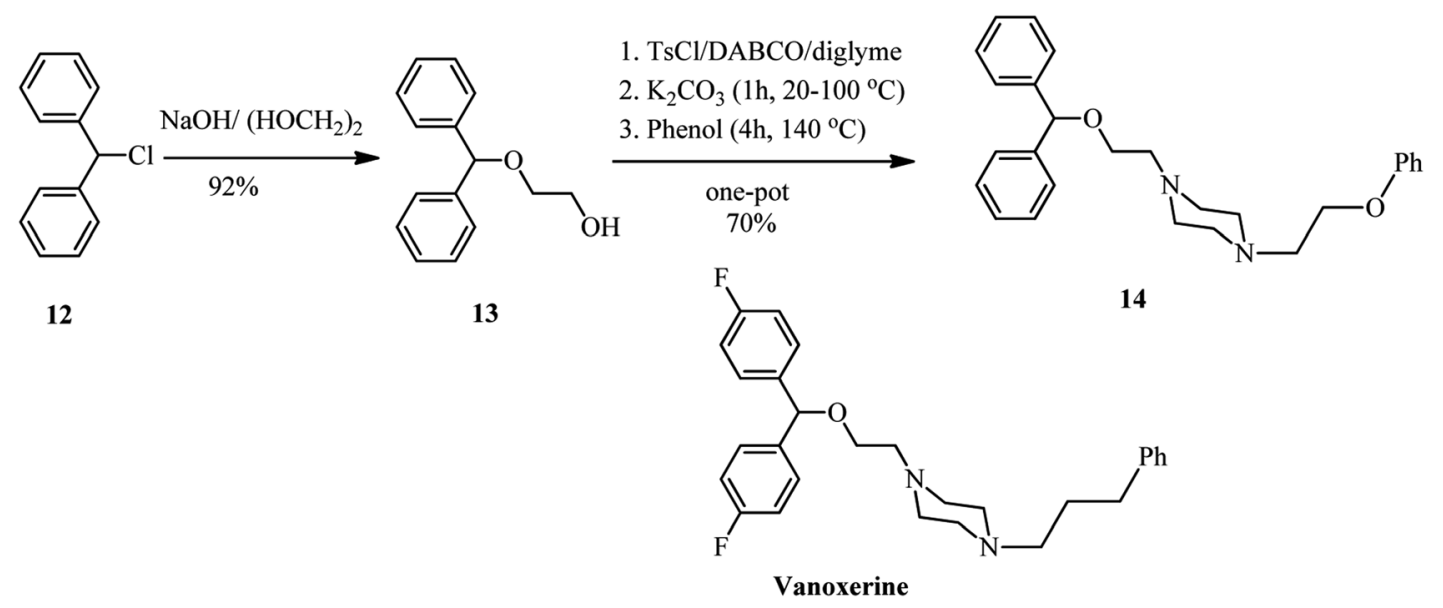

Scheme 4 Synthesis of ether isosteres of Vanoxerine via DABCO bon cleavage.

high yields of piperazine derivatives $\mathbf{1 0}$. The regioselectivity and mechanism of the reaction is depending on the nature of alkyl halides on the DABCO. Generally, the alkylation reaction competes with the DABCO ring opening reaction. The ratio of products is depending on the hard-soft properties of the nucleophiles and electrophiles (HSAB theory) and the steric hindrance of the alkyl halides. For example, while in the reaction of DABCO salts containing simple alkyl groups with oxygen nucleophiles such as sodium methoxide and potassium phenoxide, the DABCO ring-opening products 10 were obtained with high to excellent regioselectivity, by using benzyl group as alkylating agents in DABCO salt and soft nucleophiles such as benzenethiolate and benzothiazole-2-thiolate, the benzylation adducts $\mathbf{1 1}$ were obtained as major product. The results of the reaction of $\mathbf{9}(\mathrm{R}=$ benzyl) with various nucleophiles is tabulated in Scheme 3. In addition, this strategy was successfully applied for the synthesis of compounds $\mathbf{1 4}$ from 12 in four steps, a prototype of a series of potential dopamine reuptake inhibitors, which can be considered as ether isosteres of Vanoxerine (Scheme 4). In this report, alkyl tosylate was applied instead of alkyl halides for DABCO bond cleavage.

In addition to alkyl halides and tosylates, Somei et al. reported that while the reaction of DABCO 1 with 1-methoxy- indole-3-carbaldehyde 15 in $\mathrm{DMF} / \mathrm{H}_{2} \mathrm{O}(3: 1, \mathrm{v} / \mathrm{v})$ at $100{ }^{\circ} \mathrm{C}$ afforded the corresponding demethylation product 16 in quantitative yield, by performing the same reaction in DMF without a proton source, the piperazine compound $\mathbf{1 7}$ can be obtained as major product in $61 \%$ yield (Scheme 5 ). ${ }^{27}$

\section{Aryl(heteroary) halides as activating agents}

The first report on using aryl halides for the preparation of DABCO salts is published by Ross et al. in $1963 .{ }^{28}$ They investigated the reactions of nitrochlorobenzenes 18 with DABCO 1 (Scheme 6). They have shown that the only product is the salt 19 and the corresponding salt I was not observed. They confirmed that the reactions are second order; first order in the chloride and first order in the amine and the formation of the intermediate I is the rate-determining step. They concluded that the reaction further proceeded via intermediate I, followed by the direct attack of another DABCO to form 19 or attack of the chloride to the methylene group of DABCO salt I to form II, and subsequently $\mathrm{S}_{\mathrm{N}^{2}}$ displacement of the chloride in II by another equivalent of DABCO molecule to form final product 19. In addition, they have shown that by using 2,4-dinitrochlorobenzene in the reaction<smiles>COn1cc(C=O)c2ccccc21</smiles>

Scheme 5 DABCO bond cleavage via the reaction of DABCO with 1-methoxy-indole-3-carbaldehyde. 


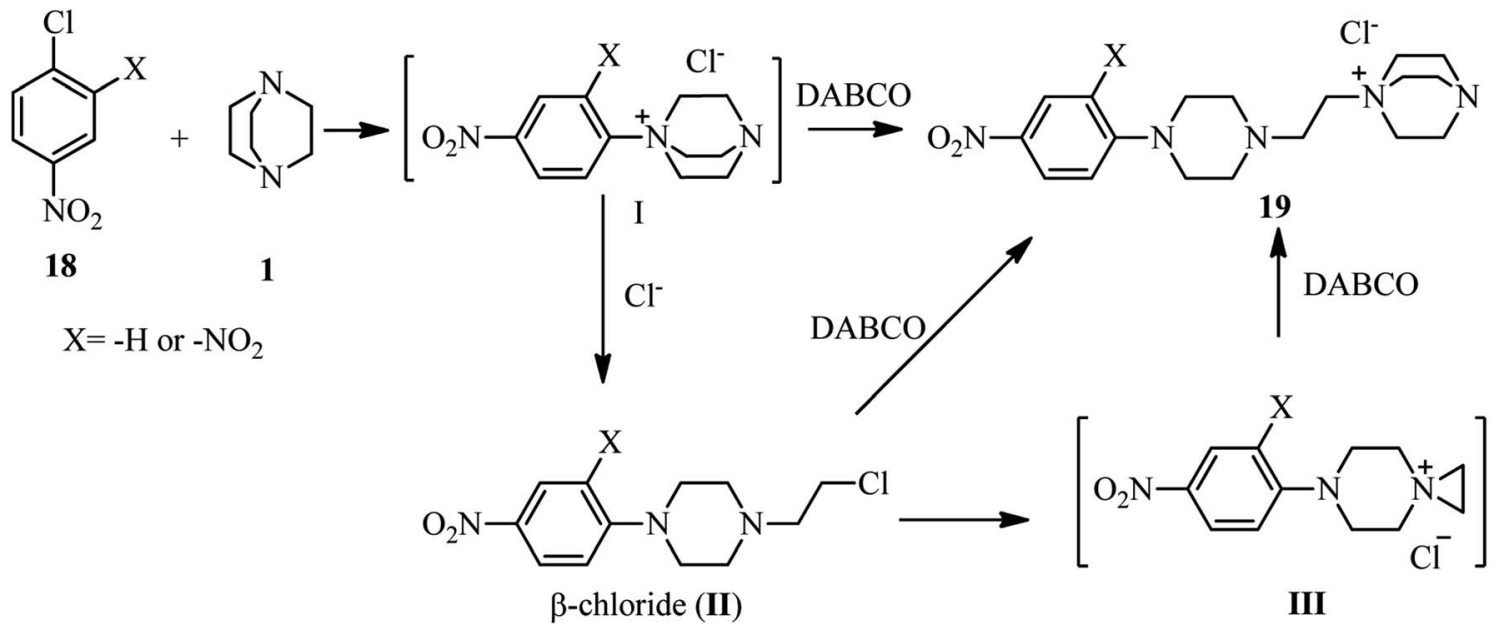

Scheme 6 Reaction of nitrochlorobenzenes with DABCO.

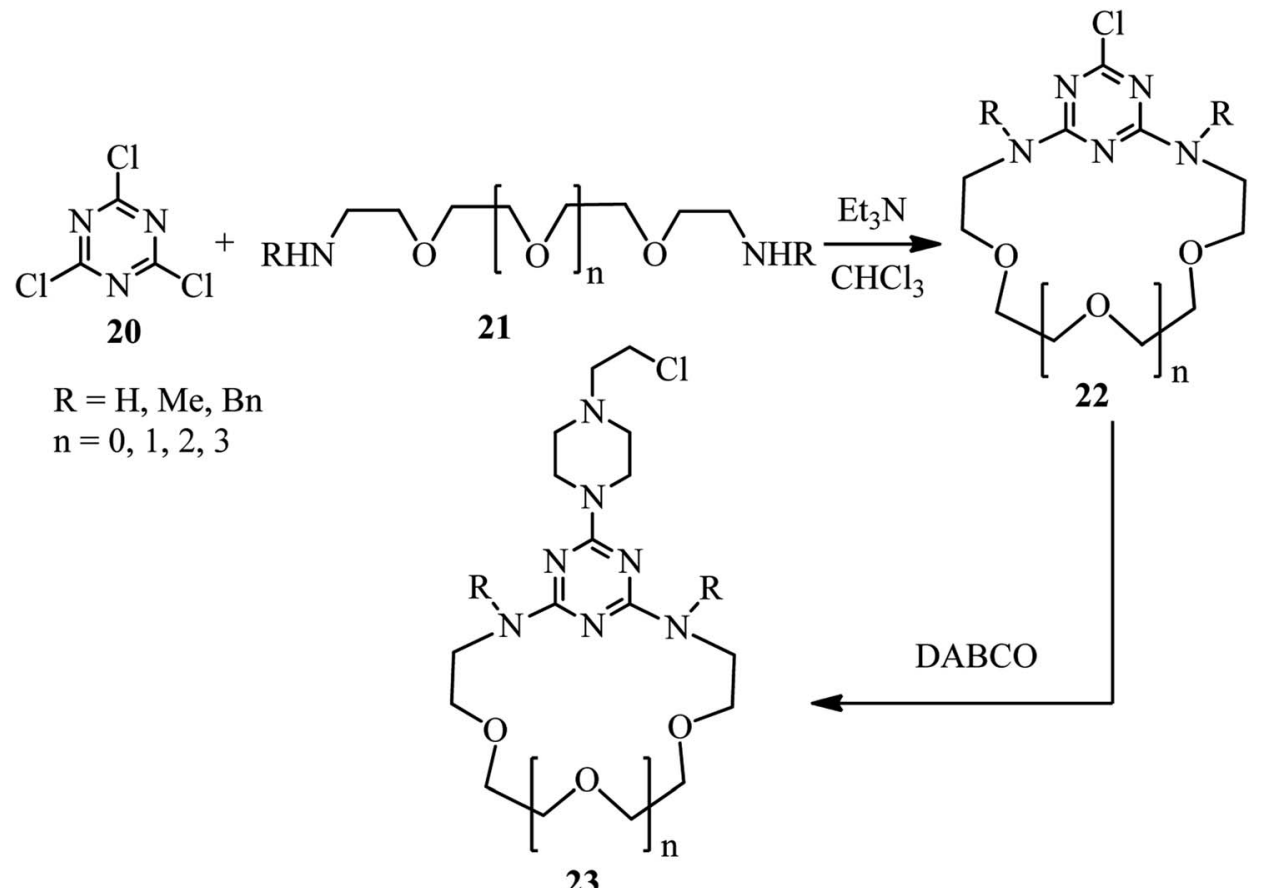

Scheme 7 Synthesis of piperazine derivatives containing aza crown ethers of various ring sizes.

with DABCO, depend on the ratio of the starting materials, the corresponding salt 19 (in the presence of excess of DABCO) or $\beta$ chloride compound II (in the presence of excess 2,4-dinitrochlorobenzene) can be obtained. They proposed that $\beta$-chloride II is converted to 19 via direct displacement or via intermediate III.

Research in this area was stopped for more than 30 years until 1996. In this year, Lutze and coworkers described that the piperazine derivatives containing aza crown ethers of various ring sizes $\mathbf{2 3}$ can be prepared by DABCO ring opening strategy in two steps (Scheme 7) ${ }^{29}$ Reaction of trichlorotriazines 20 with PEG-based diamines 21 in the presence of $\mathrm{Et}_{3} \mathrm{~N}$ as catalyst and chloroform as solvent afforded the corresponding aza crown ethers $\mathbf{2 2}$ in high yields. Reaction of these aza crown ethers $\mathbf{2 2}$ with DABCO 1 as the third component activated the methylene positions in DABCO for ring opening reaction, followed by nucleophilic attack by $\mathrm{Cl}^{-}$to afford the corresponding piperazine products 23 .

In a similar study, Kolesinska research group reported that the reaction of 2,4-bis-dialkoxy(aryloxy)-1-chlorotriazines 24 with 1 leads to the formation of 2-chloroethylamino fragment attached to 1,3,5-triazine via a piperazine ring (compound 25). ${ }^{30}$ In addition, they concluded that reaction of 2-methoxy-4,6dichloro-1,3,5-triazine 26 or trichlorotriazine 20 with excess amount of DABCO afforded the corresponding triazine backbones $\mathbf{2 7}$ or $\mathbf{2 8}$ with two or three piperazines (Scheme 8). Among the synthesized compounds, the strongest inhibition of 
<smiles>[R]Oc1nc(Cl)nc(O[R])n1</smiles><smiles>COc1nc(Cl)nc(Cl)n1</smiles><smiles>[R]Oc1nc(O[R])nc(N2CCN(CCCl)CC2)n1</smiles><smiles>COc1nc(N2CCN(CCCl)CC2)nc(N2CCN(CCCl)CC2)n1</smiles>

$\mathrm{Cl}$<smiles>ClCCN1CCN(c2nc(N3CCN(CCCl)CC3)nc(N3CCN(CCCl)CC3)n2)CC1</smiles>

Scheme 8 Synthesis of piperazines via the reaction of chlorotriazines with various equivalents of DABCO.

proliferation for tumour cells was observed for triazines with single chloroethylamino fragment.

In 2007, Wang and coworkers reported a highly efficient, two-step procedure for the synthesis of 4-substituted 1-heteroarylpiperazines 31 or $\mathbf{3 2}$ via microwave heating of heteroaryl chlorides 29 or 30 with DABCO and a nucleophile at $160{ }^{\circ} \mathrm{C}$ (Scheme 9). ${ }^{31}$ Various heteroaromatics including chloropyrimidines, 2-chloropyridines with electron withdrawing groups, 2-chlorobenzoxazole, 2-chlorobenzothiazole, and 4-chloro-2phenylquinazoline were applied successfully in this protocol.<smiles>Clc1[X]cccn1</smiles><smiles>N#[W]c1nc(Cl)[Y](=O)c2ccccc12</smiles><smiles>NCCN1CCN(c2[X]cccn2)CC1</smiles>

31 or $\quad 23$ compounds

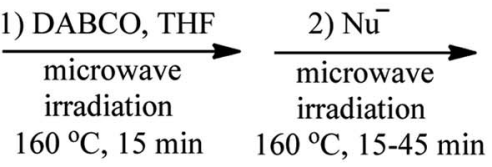<smiles>CC(C)(C)[Y]1c(N2CCN(CCN)CC2)nc2ccccc12</smiles>

32

$\mathbf{N u}=\mathrm{PhSNa}, \mathrm{MeSNa}, \mathrm{PhOK}, \mathrm{NaOMe}, \mathrm{AcONa}, \mathrm{NaOH}$, Indole, Potassium benzoate, Potassium phthalimide, Piperidine, KF, and $\mathrm{NaCH}\left(\mathrm{CO}_{2} \mathrm{Et}\right)_{2}$

Scheme 9 Microwave-assisted DABCO bond cleavage using heteroaryl chlorides. 
<smiles>C1=NCCCC1</smiles>
33<smiles>CCN1CCC(CCCl)CC1</smiles>

intermediate

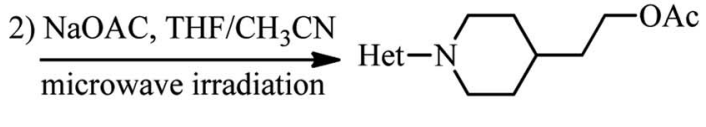

34

Scheme 10 Microwave assisted quinuclidine $\mathrm{C}-\mathrm{N}$ bond cleavage.

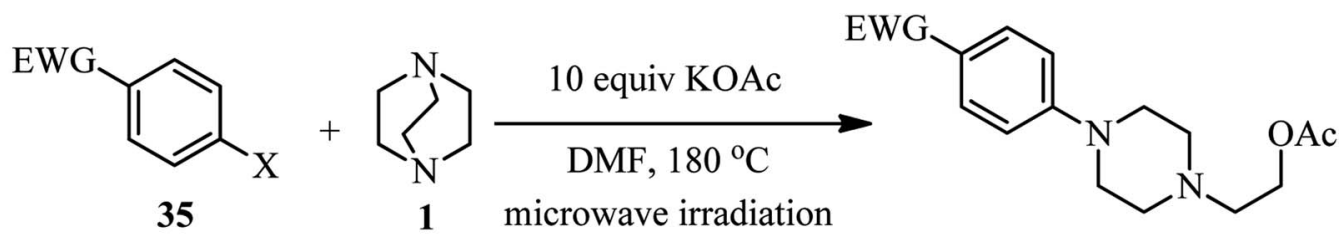

$$
\begin{gathered}
\mathbf{E W G}=-\mathrm{NO}_{2},-\mathrm{CN},-\mathrm{COCH}_{3},-\mathrm{COPh},-\mathrm{SO}_{2} \mathrm{CH}_{3},-\mathrm{CF}_{3} \quad \mathbf{3 6} \text { (9-68\% yields) } \\
\mathbf{X}=\mathrm{Cl}, \mathrm{Br}, \mathrm{I}
\end{gathered}
$$

Scheme 11 Microwave-assisted DABCO ring opening using $p$-substituted halobenzenes.

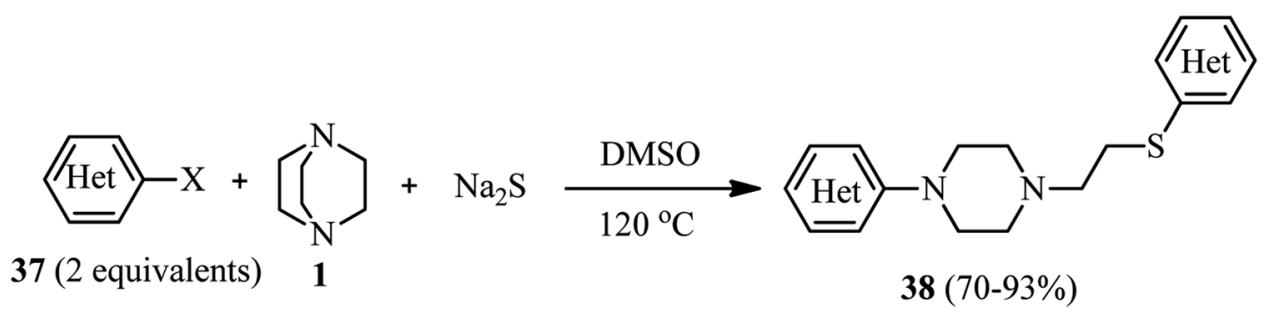

Heteroarenes: 2-halopyridines, 2-halopyrimidines, 2-bromopyrazine, and 2-haloquinoxaline

Scheme 12 Reaction of azaarene halides, $\mathrm{DABCO}$, and $\mathrm{Na}_{2} \mathrm{~S}$ for synthesis of piperazine derivatives.

In addition, a range of nucleophiles including the salt of phenol, methylmercaptan, thiophenol, alcohols, carboxylic acids, phthalimide, indole, diethylmalonate, $\mathrm{KF}$ and $\mathrm{NaOH}$ were used in this protocol to afford the corresponding piperazines in moderate to excellent yields.

In addition, the same group developed this technology for the synthesis of $N$-heteroaryl-4-(2-chloroethyl)piperidines 34 by using quinuclidine 33 instead of DABCO and their subsequent nucleophilic displacement by sodium acetate (Scheme 10). ${ }^{32}$

Microwave-assisted one-pot three-component synthesis of 1(para-substituted-aryl)-4-(2-acetoxyethyl)piperazines $\mathbf{3 6}$ is further developed by Gladstone $e t$ al. ${ }^{33}$ They have shown that mixing of a para-substituted halobenzene 35 ( 1 equiv.), DABCO 1 (2 equiv.), and potassium acetate (10 equiv.) in DMF in a microwave reactor and irradiating the mixture to reach $180{ }^{\circ} \mathrm{C}$ for 1-4 $\mathrm{h}$, the piperazine adducts 36 can be obtained in 9-68\% isolated yields (Scheme 11). Various electron-withdrawing groups such as $-\mathrm{NO}_{2},-\mathrm{COCH}_{3},-\mathrm{CN},-\mathrm{COPh},-\mathrm{SO}_{2} \mathrm{CH}_{3}$, and $-\mathrm{CF}_{3}$ can be applied on the para-position of the aryl halide. Carboxylic acid and ester are not suitable groups for the activation of aryl halide toward $\mathrm{S}_{\mathrm{N}} \mathrm{Ar}$ reaction. In addition, using 3chloro-2-cyanothiophene instead of aryl halide gave moderate yields in this protocol. By using 4-bromo-3-chloronitrobenzene, the $\mathrm{S}_{\mathrm{N}} \mathrm{Ar}$ reaction of $\mathrm{DABCO}$ was occurred regioselectively on the bromide position. By using other nucleophiles such as potassium phthalimide, potassium cyanide, potassium hydroxide, and sodium methoxide instead of potassium acetate, only the potassium phthalimide gave similar yields and no product was detected with other nucleophiles.

Efficient protocols for the synthesis of potentially drug-like compounds containing amine, azaarene, thioether, or phenol ether functionalities were introduced by Zhu et al. ${ }^{34}$ They have shown that the reaction of various azaarene halides $37(2$ equiv.), DABCO 1, and $\mathrm{Na}_{2} \mathrm{~S}$ (1 equiv.) in DMSO at $120{ }^{\circ} \mathrm{C}$ afforded the corresponding 4-substituted 1-heteroarylpiperazines 38 in high to excellent yields. While azaarene fluorides were applied as well as bromides and chlorides in this protocol, they indicated that the leaving group does not have significant effect on the reactivity in this protocol (Scheme 12).

Encouraged by these results, they also developed a one-pot four-component protocol for the synthesis of substituted piperazines 40 using an azaarene halide 37, DABCO 1, an activated aryl halide 39, and $\mathrm{Na}_{2} \mathrm{~S}$ (Scheme 13). While 2-bromopyridines were tolerated well in this multicomponent protocol, 


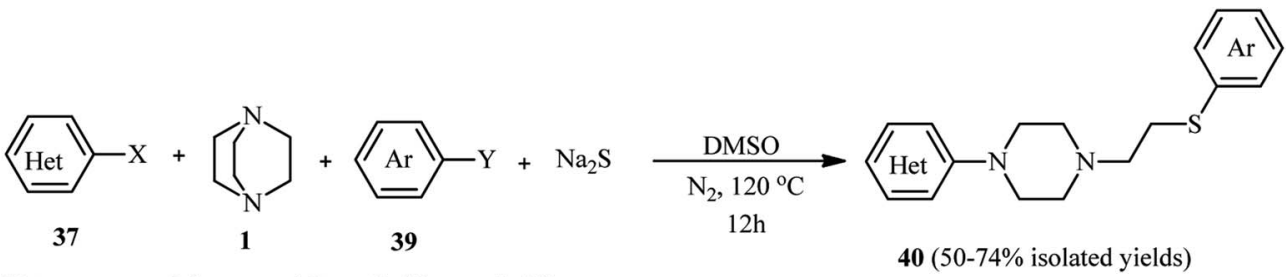

Heteroarenes: 2-bromopyridines, 2-chloropyrimidines

Aryl halides:<smiles>O=[N+]([O-])c1ccc(Br)cc1</smiles><smiles>O=[N+]([O-])c1ccccc1Br</smiles><smiles>O=[N+]([O-])c1ccc(Br)c([N+](=O)[O-])c1</smiles><smiles>CC(=O)c1ccc(F)cc1</smiles>

Scheme 13 One-pot four-component reaction for the synthesis of piperazine derivatives

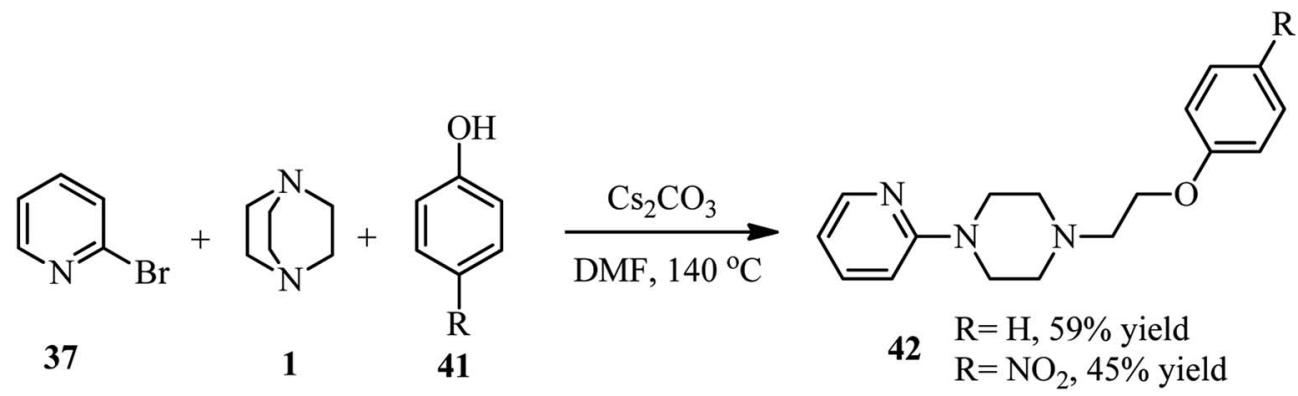

Scheme $14 \mathrm{Cs}_{2} \mathrm{CO}_{3}$-catalyzed DABCO bond cleavage using 2-bromopyridine and phenols.

the one-pot four-component reaction of aryl halides with 2chloropyrimidines, $\mathrm{DABCO}$, and $\mathrm{Na}_{2} \mathrm{~S}$ did not proceed, and only the three-component products $\mathbf{3 8}$ were obtained. According to the author's statement, it is due to the higher reactivity of 2chloropyrimidines toward $\mathrm{Na}_{2} \mathrm{~S}$ than activated aryl halides. To overcome this drawback, a two-step sequential procedure, in which $\mathrm{Na}_{2} \mathrm{~S}$ and activated aryl halides are pre-mixed prior to the addition of chloropyrimidine and DABCO, was applied and afforded the desired 4-component product in high yields. Fortunately, by developing this two-step sequential reaction process, the structure of the products can be simply tuned by changing the reactant-addition sequence.

Furthermore, they have developed that besides the aryl thiolate, phenolates $\mathbf{4 1}$ can also be utilized as nucleophiles for the three component reaction. They have shown that reaction of phenols 41 with DABCO 1 and 2-bromopyridine 37 in the presence of $\mathrm{Cs}_{2} \mathrm{CO}_{3}$ at $140{ }^{\circ} \mathrm{C}$ in DMF afforded 1-(2phenoxyethyl)-4-(pyridine-2-yl)piperazines 42 in $45-59 \%$ yields (Scheme 14).

This protocol was successfully applied for the synthesis of analgesic ruzadolane $\mathbf{4 5}$ (Scheme 15). For this purpose, the onepot three-component reaction of 1,2,4-trifuorobenzene 43, DABCO 1, and $[1,2,4]$ triazolo[4,3-a]pyridine-3-thiol 44 in the presence of $\mathrm{K}_{3} \mathrm{PO}_{4}$ and $\mathrm{KI}$ was carried out to provide the desired drug in $55 \%$ yield at $180{ }^{\circ} \mathrm{C}$ for $72 \mathrm{~h}$, or $52 \%$ yield under microwave heating for $20 \mathrm{~h}$.

Recently, the same group reported a novel one-pot three component reaction for the synthesis of aromatic aminoalkyl esters 46 via a direct $\mathrm{C}-\mathrm{N}$ esterification/arylation reaction. For this purpose, reactions of an activated aryl halide (4-bromonitrobenzene) or a variety of pyridyl halides with carboxylic acids and DABCO were carried out in the presence of $100 \mathrm{~mol} \%$ of<smiles>Fc1ccc(F)c(F)c1</smiles>

Scheme 15 Synthesis of ruzadolane via DABCO bond cleavage strategy. 
<smiles></smiles>

46, 22 examples

$62-95 \%$ isolated yields

Scheme 16 Carboxylic acids and anhydrides as nucleophile in DABCO bond cleavage.

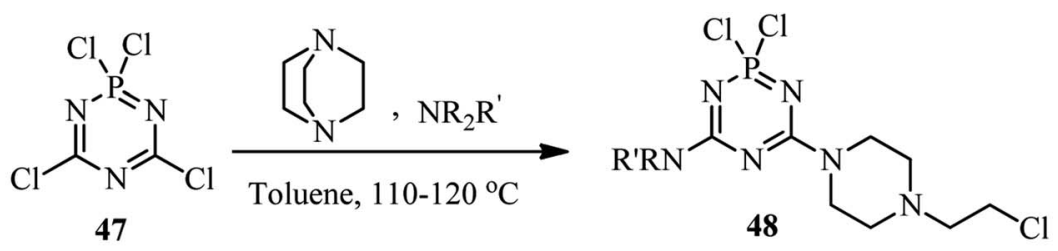

$\mathrm{NR}_{2} \mathrm{R}^{\prime}=\mathrm{Et}_{3} \mathrm{~N},(n-\mathrm{Pr})_{3} \mathrm{~N},(\text { iso- } \mathrm{Pr})_{2} \mathrm{EtN},\left(\mathrm{Me}_{2} \mathrm{~N}\right)_{2} \mathrm{CH}_{2}$<smiles>ClC1=NC(Cl)=NP(Cl)(Cl)=N1</smiles>

47

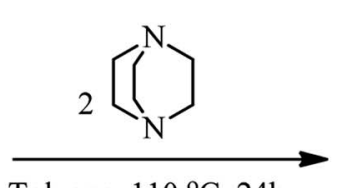

Toluene, $110^{\circ} \mathrm{C}, 24 \mathrm{~h}$<smiles>ClCCN1CCN(C2=NC(N3CCN(CCCl)CC3)=NP(Cl)(Cl)=N2)CC1</smiles>

49

Scheme 17 Synthesis of 4-(2-chloroethyl)piperazino derivatives of carbaphosphazenes.

$\mathrm{Cs}_{2} \mathrm{CO}_{3}$ in DMF at $140 \mathrm{C}$ for $12 \mathrm{~h}$ (Scheme 16). ${ }^{35}$ The products were obtained in high to excellent yields. In addition, they have shown that acid anhydrides can be used instead of carboxylic acids in this protocol under similar conditions. They also confirmed that the reactivity of carboxylic acids and anhydrides was not affected by the steric hindrance of substituents. In addition, $N$-methylpyrrolidine was applied successfully in this protocol instead of DABCO to afford the corresponding linear aminoesters in high yields.
The activation of DABCO by novel heteroarenes is further investigated using carbaphosphazenes. In this case, Reddy et al. developed a new method for preparing 4-(2-chloroethyl)piperazino derivatives of carbaphosphazenes 48 and 49 via the reaction of DABCO and tetrachlorocyclodicarbaphosphatriazene $\mathbf{4 7}$ (Scheme 17). ${ }^{36}$ By using an equimolar amount of $\mathbf{4 7}, \mathbf{1}$, and an acyclic tertiary amine, the corresponding piperazino heterocycles 48 were obtained in $32-82 \%$ isolated yields. Beside the DABCO, a range of tertiary amines was utilized as a third component in<smiles>[R]n1cnc2c(OS(=O)(=O)c3c(C)cc(C)cc3C)nc(N)nc21</smiles>

50<smiles>CC(=O)On1ccccc1=S</smiles>

51<smiles>[R]n1cnc2c(Sc3cccc[n+]3[O-])nc(N)nc21</smiles>

$52(51-55 \%)$<smiles>[R]n1cnc2c(N3CCN(CCSc4cccc[n+]4[O-])CC3)nc(N)nc21</smiles>

$\mathrm{R}=$

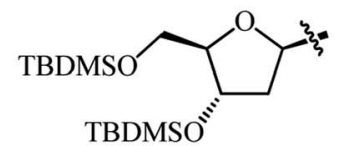

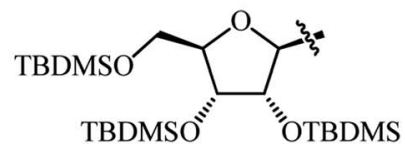

Scheme 18 Synthesis of piperazine substituted nucleoside via DABCO bond cleavage. 
$1: 1: 1$ molar ratio to increase the diversity of the reaction and solubility of the products. In addition, quinuclidine was applied successfully instead of DABCO in this protocol. Other cyclic tertiary amines such as $N$-methylmorpholine and $N$-methylpiperidine did not show any evidence of ring cleaved products. They also have shown that the reaction of 47 with DABCO in $1: 2$ molar ratio afforded the bis piperazino product 49 in $56 \%$ yield via two DABCO ring opening reactions by chloride attack. The cleaved alkyl group of DABCO remains as an alkyl chloride on the product molecule.

Finally, during the introducing of $N$-hydroxypyridine-2(1H)thione (NHPT) $\mathbf{5 1}$ at the 6-position of 2'-deoxyguanosine $\mathbf{5 0}$ in the presence of DABCO, Vrantza et al. observed that the corresponding piperazine substituted nucleoside $\mathbf{5 3}$ were obtained as side products in $30-34 \%$ yields (Scheme 18). ${ }^{37}$ In fact, DABCO has dual role as catalyst and reactant in this protocol. The reaction proceeded via DABCO attack to the position 6 of the nucleoside 50, then S-nucleophilic attack of NHPT at the $\alpha$-C-atom of the positively charged DABCO-purine intermediate, followed by an $\mathrm{S}_{\mathrm{N}^{2}}$ addition and opening of the ethylene DABCO bridge.

\section{Benzynes as activating agents}

Benzynes are momentous intermediates for the preparation of significant scaffold in chemistry. Using benzynes as activator for DABCO bond cleavage is developed by Min et al. ${ }^{38}$ For this purpose, a one-pot three-component reaction of an equivalent of a benzyne precursor 54 [2-(trimethylsilyl)phenyl trifluoromethanesulfonate or its derivatives], two equivalents of DABCO 1, and an excess amount of a nucleophile in the present of an equivalent of $\mathrm{CsF}$ in $\mathrm{CH}_{3} \mathrm{CN}$ at $100{ }^{\circ} \mathrm{C}$ for $18 \mathrm{~h}$ was carried out to afford the 2-(4-arylpiperazin-1-yl)ethyl-containing molecules 55 in $18-98 \%$ isolated yields. Beside thiols, other nucleophiles such as methyl acrylate, allyl acetate, methyl acetate, fluoride, and 2,4-pentanedione participated well in the DABCO ring opening reaction to form $\mathrm{C}-\mathrm{O}, \mathrm{C}-\mathrm{C}$, and $\mathrm{C}-\mathrm{F}$ bonds (Scheme 19).

The mechanism of this reaction is proposed in Scheme 20. The benzyne $\mathbf{5 6}$ generated in situ from $\boldsymbol{o}$-silyl aryl triflates $\mathbf{5 4}$ and CsF is attacked by DABCO 1 to generate zwitterion intermediate ammonium salt 57. The intermediate $\mathbf{5 7}$ undergoes ring

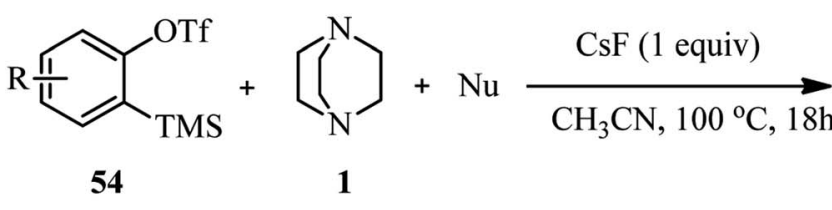

Nu: aromatic and aliphatic thiols, methyl acrylate allyl acetate, methyl acetate, fluoride, and 2,4-pentanedione<smiles>NCCN1CCN(c2cc#[R]cc2)CC1</smiles>

Scheme 19 DABCO bond cleavage by in situ prepared benzyne and a nucleophile.

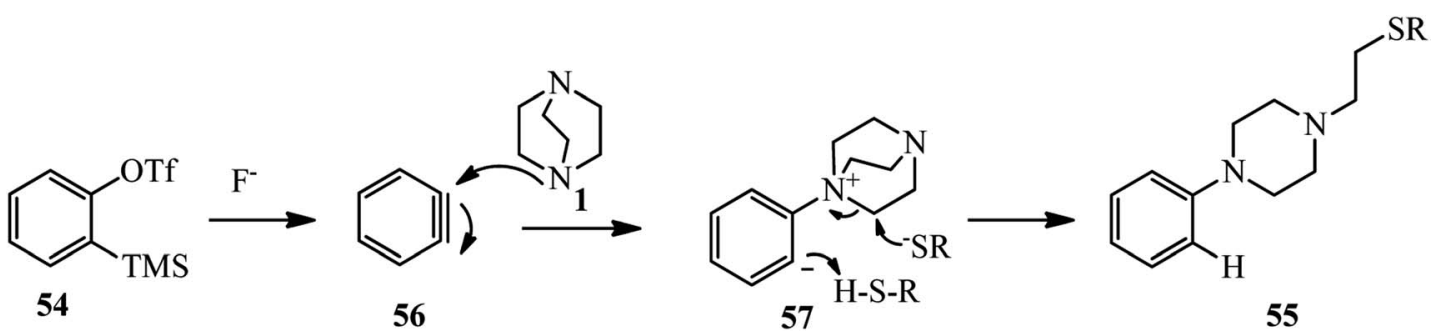

Scheme 20 Proposed mechanism for DABCO bond cleavage by in situ prepared benzyne.

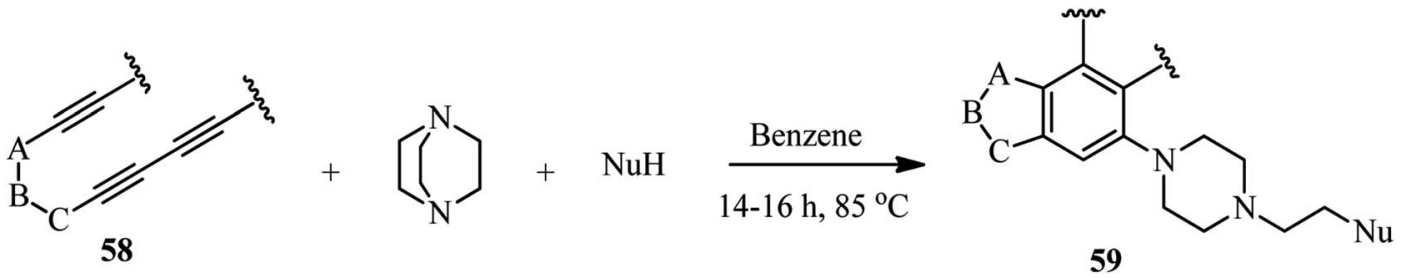

$$
\begin{aligned}
& \mathbf{A}=\mathrm{CH}_{2} \text { and } \mathrm{C}=\mathrm{O} \\
& \mathbf{B}=\mathrm{NMs}^{\mathrm{CH}}, \mathrm{O}, \mathrm{NH} \text { and } \mathrm{NBoc} \\
& \mathbf{C}=\mathrm{CH}_{2}, \mathrm{NMs}, \mathrm{NBoc} \text { and } \mathrm{C}\left(\mathrm{CH}_{3}\right)_{2}
\end{aligned}
$$

NuH : Phenols, 2-hydroxypyridine, 3-hydroxypyridine Phthalimide, 5-hydroxyindole, $\mathrm{CHCl}_{3}$, benzotriazole, acetic acid and tetrazole

Scheme 21 One-pot three-component reaction of polyynes, DABCO, and a protic nucleophile. 


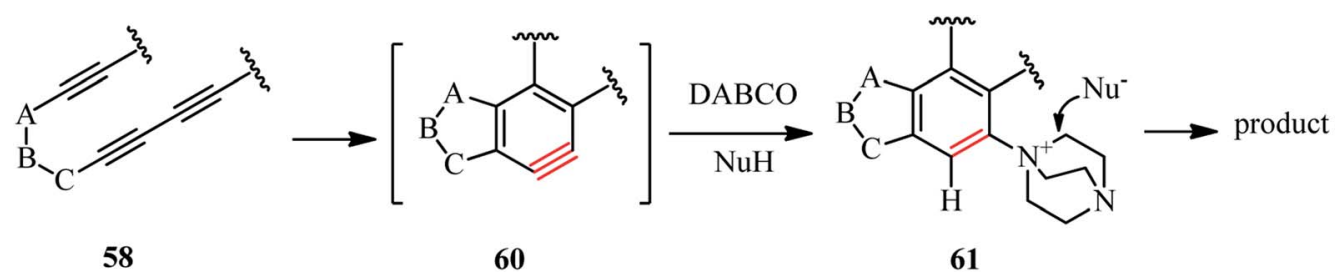

Scheme 22 Proposed mechanism for the synthesis of multiheterocyclic products from polyynes, DABCO and nucleophiles.

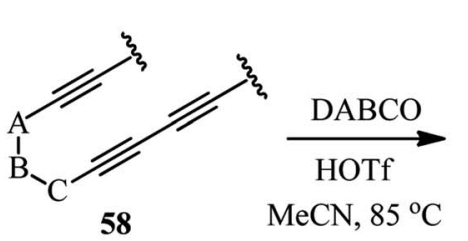

$\mathbf{A}=\mathrm{CH}_{2}$

$\mathbf{B}=\mathrm{CH}_{2}$ and $\mathrm{NMs}$

$\mathbf{C}=\mathrm{CH}_{2}$ and $\mathrm{NMs}$

$\mathrm{Nu}^{-}:$<smiles>CCOc1c([N+]23CCN(CC2)CC3)cc2c(c1C(C)(C)C)NCB2</smiles>

62<smiles>CC(=O)c1cn(N)c2ccccc12</smiles><smiles>CC(C)(C)c1c(N2CCN(CCN)CC2)cc2c(c1C(C)(C)C)N[IH]C2</smiles>

$\mathbf{5 9}$ (40-61\% yields)<smiles>COC(=O)C([NH])C(C)=O</smiles>

Scheme 23 Reaction of polyynes with DABCO in the present of trifilic acid and subsequent ring opening with a nucleophile.

opening with the aid of a nucleophile to furnish 1-ethyl-4arylpiperazine derivative $\mathbf{5 5}$.

Scheme 21 depicts a facile and highly efficient strategy for the construction of multiheterocyclic compounds which was reported by Ross and Hoye in $2018 .^{39}$ They have shown that the three-component reaction of a polyyne $\mathbf{5 8}$, DABCO, and a protic nucleophile $(\mathrm{NuH})$ afforded the corresponding multiheterocyclic products 59 in good to high yields (36-74\%). Various tri- and tetraynes were applied successfully to construct diversities of fused bicyclic compounds. In addition, various protic nucleophiles such as phenols with electron-donating and withdrawing groups, hydroxypyridines, 5-hydroxyindole, phthalimide, acetic acid, tetrazole and benzotriazole were introduced in the structure of products. By performing the reaction in chloroform solution, they have shown that chloride (from chloroform) can be introduced in the structure of product and act as nucleophile in the DABCO ring opening step.

They proposed that the thermal cycloisomerization of tethered tri- and tetraynes $\mathbf{5 8}$ leads to benzynes $\mathbf{6 0}$ under neutral conditions in a hexadehydro-Diels-Alder reaction. In the presence of DABCO and a proton source, the benzyne intermediate 60 converted to ion pair 61, followed by DABCO ring opening to

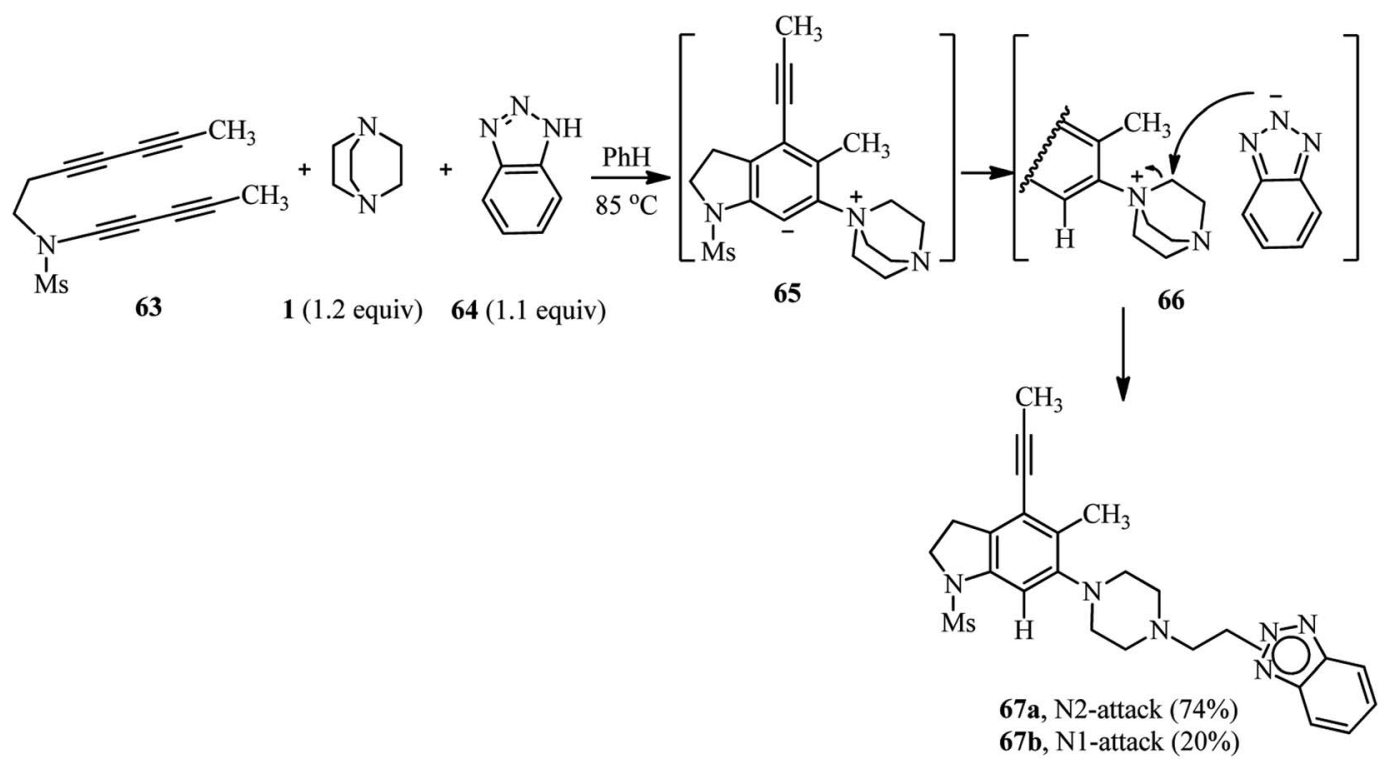

Scheme 24 One-pot three component reaction of tetrayne, DABCO and benzotriazole. 
afford the products (Scheme 22). The following criteria should be considered for this type of reaction: (i) neither the DABCO or the protic nucleophile should not react with the polyyne precursor faster than its rate of cyclization; (ii) the DABCO should add to the benzyne intermediate faster than the protic nucleophile; (iii) the protic nucleophile should be acidic enough to protonate the intermediate 1,3-zwitterion; and (iv) the conjugate base of $\mathrm{H}-\mathrm{Nu}$ should be sufficiently nucleophilic to undergo DABCO ring opening. By considering these limitations, a one-pot two-step strategy involving the formation and subsequent nucleophilic ring-opening of the intermediate $\mathbf{6 1}$ is recommended.

In addition, they have shown that by using $\mathrm{HOSO}_{2} \mathrm{CF}_{3}$ as protic nucleophile in the same reaction, the corresponding DABCO ammonium triflate intermediates 62 can be obtained, which is suitable intermediate for ring opening by various nucleophiles including sodium salts of methyl indole-3carboxylate, dimethylmalonate, and azide (Scheme 23).

The same authors have shown that trapping of the in situ prepared benzyne from tetrayne $\mathbf{6 3}$ with DABCO in the presence of benzotriazole 64 furnish the 1,3-zwitterion $\mathbf{6 5}$, and then the ammonium-benzotriazolide ion pair 66, which finally undergoes nucleophilic ring opening through the $\mathrm{N}^{1}$ - or $\mathrm{N}^{2}$ position of benzotriazolide to afford the products $67 \mathrm{a}(74 \%)$ and 67b $(20 \%)$, respectively (Scheme 24). ${ }^{40}$ This approach was successfully applied for the functionalization of phenolic natural products such as vitamin $\mathrm{E}$ and estradiol. By heating tetrayne (1 equiv.), DABCO (1.2 equiv.), and vitamin $\mathrm{E}$ (1.1 equiv.) (Scheme 25, right) or estradiol (1.1 equiv.) (Scheme 25, down) in benzene at $85{ }^{\circ} \mathrm{C}$, the corresponding products 68 and 69 were obtained in $64 \%$ and $79 \%$, respectively. Although estradiol contains both alcoholic and phenolic groups in the structure as potential nucleophiles, the reaction proceeded chemoselectively via the phenolic group.

\section{Transition-metal catalyzed DABCO bond cleavage}

Transition-metal catalyzed $\mathrm{C}-\mathrm{H}$ activation in aryl rings or $\mathrm{C}-\mathrm{X}$ activation in aryl and vinyl halides is an efficient strategy for the synthesis of DABCO salts suitable for $\mathrm{C}-\mathrm{N}$ bond cleavage. For this purpose, a one-pot two-step procedure for the regioselective synthesis of aryl piperazines $\mathbf{7 2}$ from the corresponding $\mathrm{C}-\mathrm{H}$ compounds and Selectfluor ${ }^{\circledR}$ as DABCO derivative is developed by Boursalian et al. under irradiation-free conditions (Scheme 26). ${ }^{41}$ This reaction was catalyzed by a dual catalyst combination: a palladium complex $71(2.5 \mathrm{~mol} \%)$ and $\mathrm{Ru}(\mathrm{bipy})_{3}\left(\mathrm{PF}_{6}\right)_{2}(7.5 \mathrm{~mol} \%)$. They hypothesized that a singleelectron reduction of Selectfluor ${ }^{\circledR}$ provided the corresponding doubly cationic radical TEDA ${ }^{2+}$ (TEDA, $N$-(chloromethyl)triethylenediamine), which is capable to undergo radical aromatic substitution to give $N$-aryl- $N^{\prime}$-chloromethyldiazoniabicyclo [2.2.2] octane salts $\left(\mathrm{Ar}^{-T E D A}{ }^{2+}\right)$. The reaction was continued by reduction of $\mathrm{Ar}^{-T E D A}{ }^{2+}$ compounds by sodium thiosulfate. Various arenes including five- and six-membered (hetero)arenes undergo piperazination in this protocol. The site of piperazination can be determined by directing group on the aromatic system.

$\mathrm{Cu}(\mathrm{I})$-catalyzed synthesis of $N$-alkyl- $N^{\prime}$-aryl-piperazines $73 \mathrm{via}$ a one-pot three-component reaction of DABCO, alkyl halides, and aryl halides is reported by Yavari et al. in 2014. The reactions were carried out in the presence of a catalytic amount of copper iodide ( $5 \mathrm{~mol} \%$ ) and $\mathrm{KO} t \mathrm{Bu}$ as base in DMSO at $65{ }^{\circ} \mathrm{C}$. Alkyl chlorides and bromides and aryl bromides and iodides were applied successfully in this protocol to afford the unsymmetrical piperazines in high to excellent yields (Scheme 27). ${ }^{42}$

The proposed mechanism by authors is depicted in Scheme 28. They proposed that the crucial step is the formation of DABCO salt 9. This salt then coordinated to CuI via free

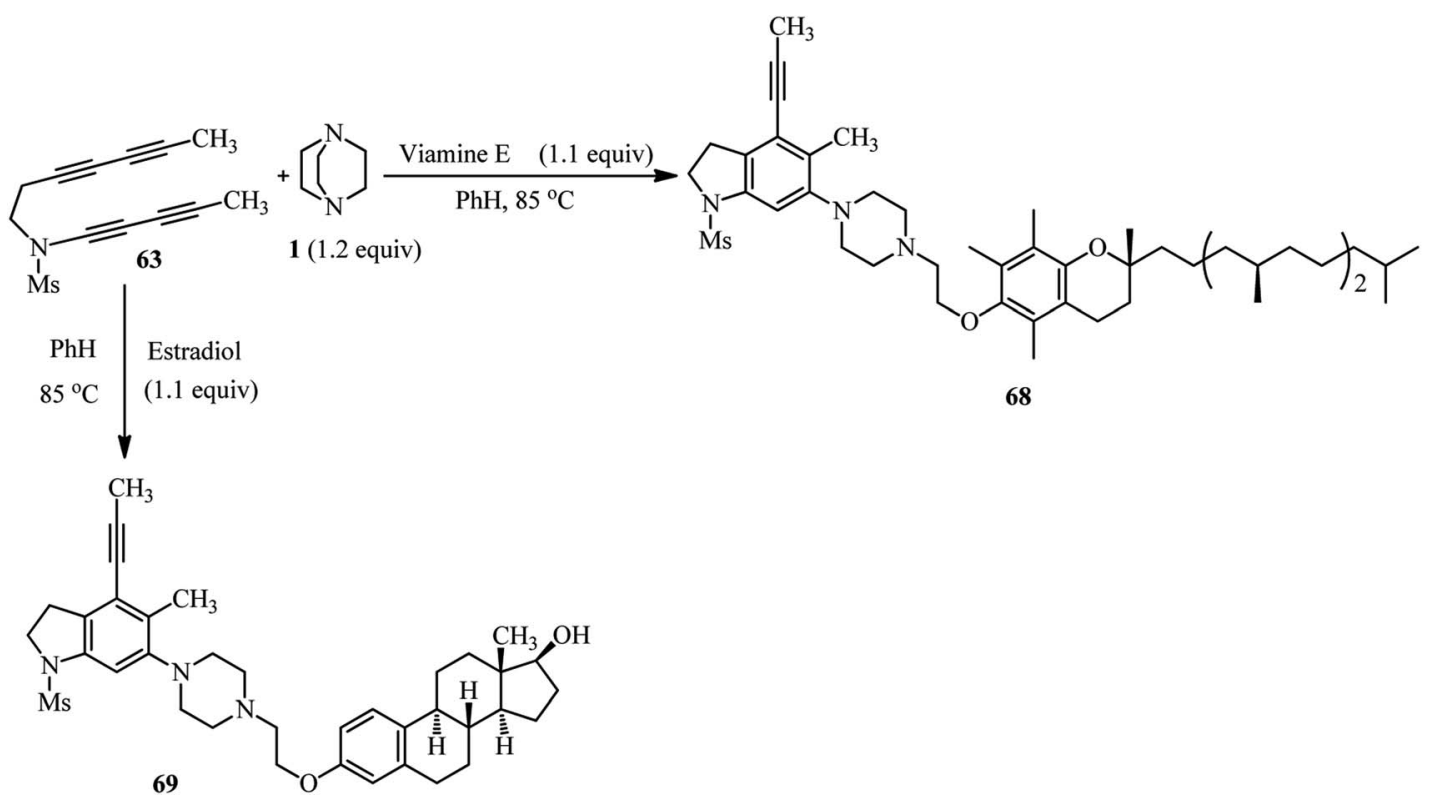

Scheme 25 Utilization of phenolic natural products as nucleophiles in benzyne-activated DABCO bond cleavage. 
1) 1.5 equiv. selectfluor,

\section{$2.5 \mathrm{~mol} \% 71$,}<smiles>c1ccccc1</smiles>

$7.5 \mathrm{~mol} \% \mathrm{Ru}(\text { bipy })_{3}\left(\mathrm{PF}_{6}\right)_{2}$

$\mathrm{MeCN}, 23{ }^{\circ} \mathrm{C}$

2) $\mathrm{Na}_{2} \mathrm{~S}_{2} \mathrm{O}_{3}, \mathrm{H}_{2} \mathrm{O}, 100^{\circ} \mathrm{C}$

70<smiles>ClCN1C2CC[N+]1(CCl)CC2</smiles>

TEDA $^{2+\bullet}$

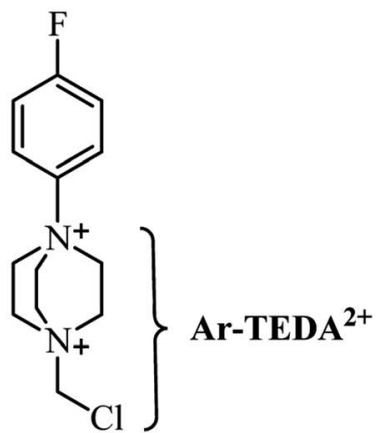<smiles>[R]c1ccc(N2CCNCC2)cc1</smiles>

72 (23 examples) $45-91 \%$ yields<smiles>BrC(Br)(Br)Br</smiles>

Scheme 26 Transition-metal catalyzed piperazination of arenes.

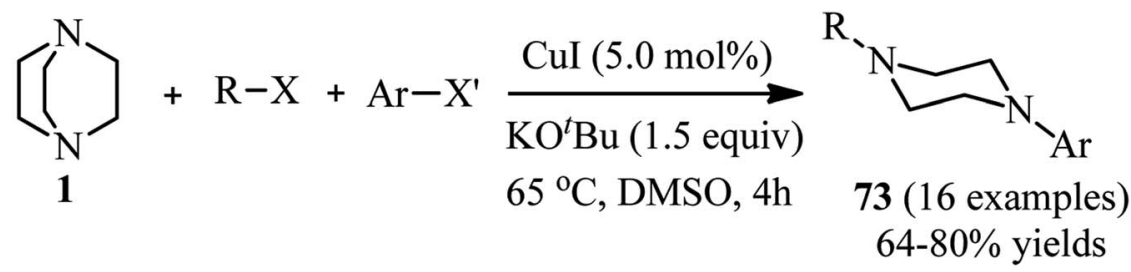

$\mathrm{R}=$ Benzyl, $n$-hexyl $\quad \mathrm{Ar}=$ phenyl rings with electron-donating $\mathrm{X}=\mathrm{Cl}, \mathrm{Br} \quad \mathrm{X}^{\prime}=\mathrm{Br}$, I and -withdrawing groups

Scheme $27 \mathrm{Cu}(\mathrm{I})$-catalyzed synthesis of $N$-alkyl- $N^{\prime}$-aryl-piperazines.
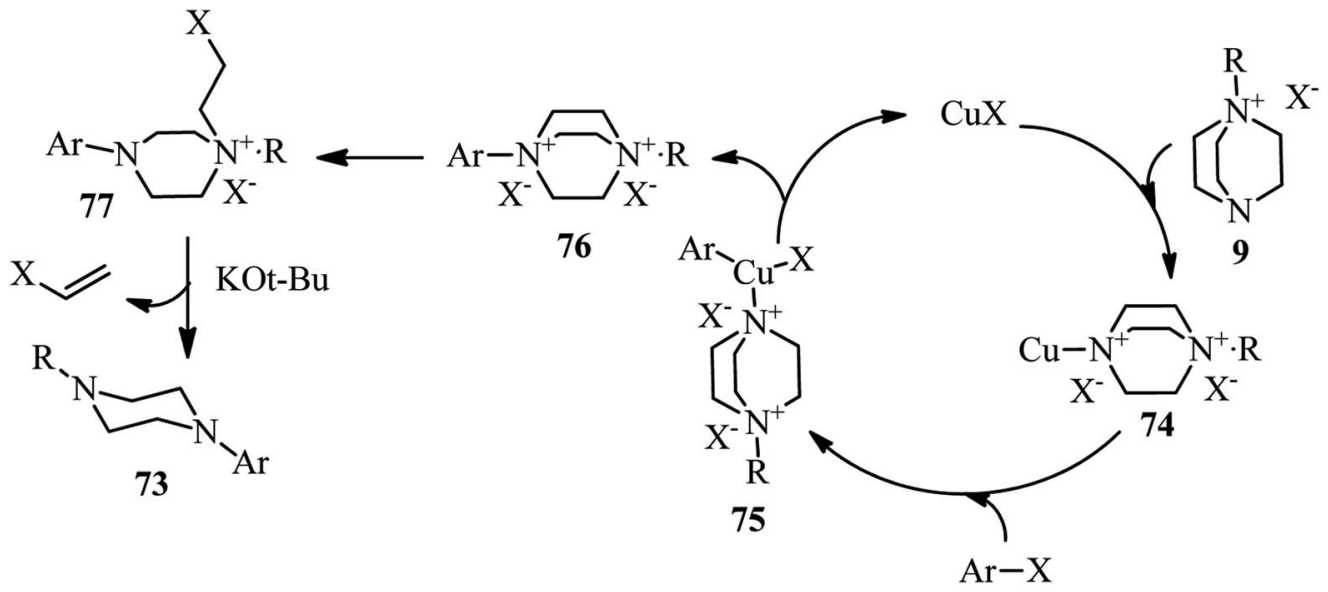

Scheme 28 Proposed mechanism for $\mathrm{Cu}(\mathrm{I})$-catalyzed synthesis of $N$-alkyl- $N^{\prime}$-aryl-piperazines.

nitrogen atom to afford the intermediate $\mathbf{7 4}$. Then, aryl halide could be oxidatively added to the $\mathrm{Cu}(\mathrm{I})$-complex $\mathbf{7 4}$ to form $\mathrm{Cu}(\mathrm{III})$-intermediate 75 . Reductive elimination of the intermediate 75 could provide the ammonium salt $\mathbf{7 6}$. This intermediate undergoes nucleophilic displacement by chloride ion to afford the intermediate 77, followed by Hofmann elimination in the presence of a base to furnish the final product 73. The proposed mechanism is supported by the fact that iodoethylene can be detected in GC-MS analysis.

In addition, the synthesis of unsymmetrical piperazines with the same strategy is further developed by GhazanfarpourDarjani and coworkers. ${ }^{43}$ They have utilized alkyl chlorides, 
A)

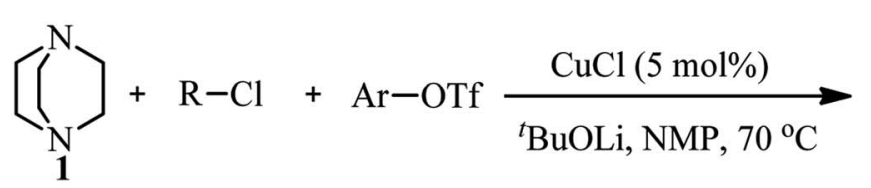

$\mathrm{R}=\mathrm{Bn}, n-\mathrm{Bu}, n-\mathrm{Hexyl}$

Ar: aromatic and heteroaromatics<smiles>[Te]N1CCN(Cc2ccccc2)CC1</smiles>

B)

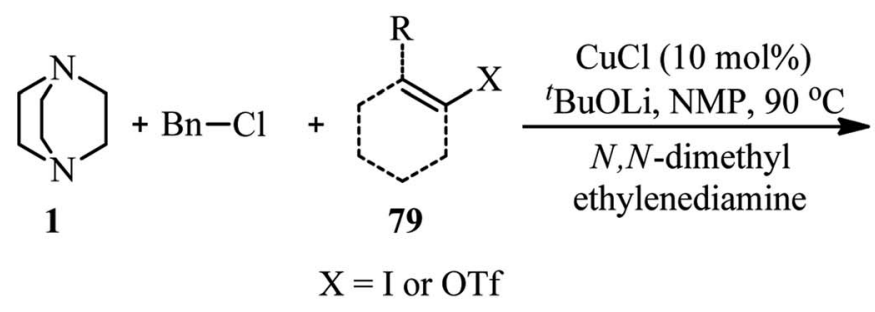

$\mathrm{Bn}$ $73-93 \%$ yields Scheme $29 \mathrm{Cu}(\mathrm{I})$-catalyzed synthesis of piperazines using aryl triflates or alkenyl iodides (triflates).

aryl(heteroaryl) triflates and DABCO under optimal reaction conditions [ $\mathrm{CuCl}$ ( $5 \mathrm{~mol} \%), t$-BuOLi (1.5 equiv.), and NMP as solvent at $70{ }^{\circ} \mathrm{C}$ for $14 \mathrm{~h}$ ] to provide $N$-alkyl- $N^{\prime}$-aryl (heteroaryl) piperazines 78 in $73-93 \%$ yields. They also concluded that by using alkenyl triflates $\mathbf{7 9}$ instead of aryl triflates or aryl iodides, the corresponding $N$-alkyl- $N^{\prime}$-alkenyl piperazines 80 can be prepared in $46-89 \%$ yields. The use of $N, N^{\prime}$-dimethyl ethylenediamine as ligand and performing the reactions at higher temperature $\left(90^{\circ} \mathrm{C}\right)$ is crucial for this reaction. Both external and internal alkenyl iodides (triflates) are suitable substrates in this protocol (Scheme 29).

\section{Pyridine- $\mathrm{N}$-oxides as activating agents}

Bugaenko et al. reported that the quaternary $N$-(2-pyridyl)DABCO salts 82 can be simply prepared by the reaction of heterocyclic $N$-oxides $\mathbf{8 1}$ with DABCO in the presence of an activating agent such as TFAA at $0{ }^{\circ} \mathrm{C}$ to $\mathrm{rt}$ for $1 \mathrm{~h}$. This intermediate 82 can be simply react with diversities of nucleophiles such as thioacetic acid, aromatic and aliphatic thiols, phthalimide, methylhydrazine, morpholine, sodium cyanide, sodium benzenesulfinate to give the functionalized $N$-(2-pyridyl)- $N^{\prime}$ ethylpiperazines 83 in moderate to excellent yields (12-96\%) via

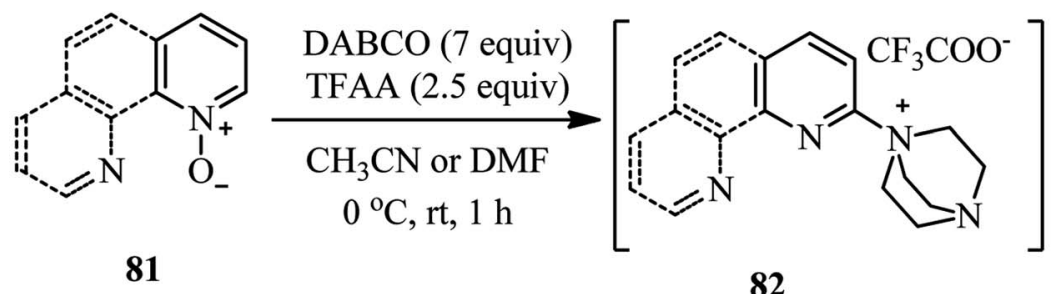

Nu: AcSH, aromatic and aliphatic thiols, sodium toluenesulfinate, sodium phthalimide, methylhydrazine, morpholine, $\mathrm{NaCN}$ and $\mathrm{NaN}_{3}$

$\mathrm{Nu}$ (4 equiv)

$\mathrm{CH}_{3} \mathrm{CN}, \mathrm{rt}, 1-24 \mathrm{~h}$ for thiols

or

DMF, $60^{\circ} \mathrm{C}$ for $24 \mathrm{~h}$

for other nucleophiles<smiles>NCCN1CCN(c2ccc3ccc4cccnc4c3n2)CC1</smiles>

83 (46 examples)

$12-96 \%$ yields 
A)

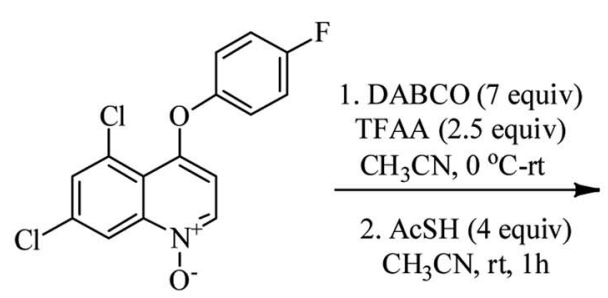

Quinoxyfen<smiles>CSCCN1CCN(c2cc(Oc3ccc(F)cc3)c3c(Cl)cc(Cl)cc3n2)CC1</smiles>

no need to column chromatography
B)<smiles>[O-][n+]1ccccc1</smiles>

\section{1. $\operatorname{DABCO}$ (7 equiv) TFAA (2.5 equiv) DMF, $0^{\circ} \mathrm{C}-\mathrm{rt}$ rt, $0.5 \mathrm{~h}$}

3. $\mathrm{RNa}, \mathrm{rt}, 24 \mathrm{~h}$

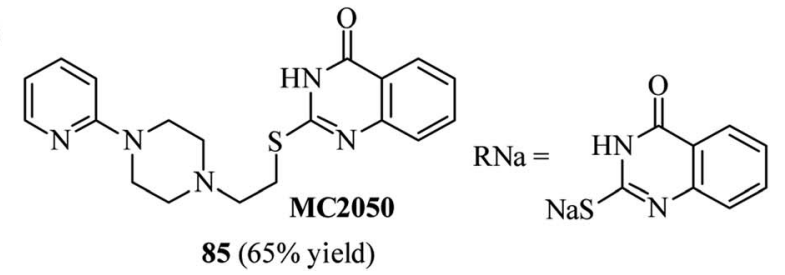

Scheme 31 Synthesis of functionalized Quinoxyfen-piperazine and MC2050 starting from pyridine-N-oxides.

DABCO ring opening reaction (Scheme 30). ${ }^{44}$ Diversely substituted pyridine $N$-oxides, quinolone- $N$-oxides, and 1,10phenanthroline 1-oxide were applied successfully in this protocol. In addition, they have confirmed that many nucleophile-sensitive and synthetically valuable functional groups including halide, ester, amide, and nitrile were perfectly tolerated in this protocol. The main advantages of this protocol including operationally simple, metal-free, one-pot synthetic procedure, mild reaction conditions, high positional selectivity, and excellent functional group tolerance are noteworthy. The potential of this protocol for the synthesis of drug-like molecules 84-85 were examined for the late stage functionalization of Quinoxyfen and for one-pot synthesis of MC2050, a potent PARP-1 inhibitor, in reasonable isolated yield $65 \%$ versus $45 \%$ in two-step process (Scheme 31$)^{45}$

Two reaction pathways for the preparation of the intermediate $\mathbf{8 2}$ are recommended by authors (Scheme 32). In both cases, activation of $N$-oxide by TFAA was considered as initial event which enhance both electrophilicity and $\mathrm{CH}$-acidity of the
$\mathrm{C}-2$ position in pyridine ring. Then, DABCO attack to the $\mathrm{C}-2$ position of $\mathbf{8 6}$, followed by deprotonation/aromatization provides the intermediate $\mathbf{8 2}$ (Scheme 32, pathway A). Alternatively, abstraction of the acidic hydrogen in position C-2 of the pyridine ring in $\mathbf{8 6}$ by DABCO can provide carbene $\mathbf{8 8}$ which is active electrophilic specie toward nucleophilic attack by DABCO. Finally, aromatization provides the salt 82 (Scheme 32, pathway B).

The same group also described that by varying the reaction conditions including raising the reaction temperature and time in both steps of the reaction $\left(0^{\circ} \mathrm{C} \mathrm{rt}\right.$ for $1 \mathrm{~h}$ and $\mathrm{rt}-90^{\circ} \mathrm{C}$ for $8 \mathrm{~h}$ for the first step; $90^{\circ} \mathrm{C}$ for overnight for the second step), it is possible to prepared the potential biologically active heterocyclic compounds 90 comprising bis(ethylpiperazine) motif. They hypothesized that the ammonium salt 91 acts as intermediate in this protocol and is reactive for further ring opening (Scheme 33). ${ }^{44}$

Interestingly, they have also shown that by using bis- $N$-oxide 92 containing two alkylated pyridine moieties in the standard protocol described in the Scheme 30, the corresponding

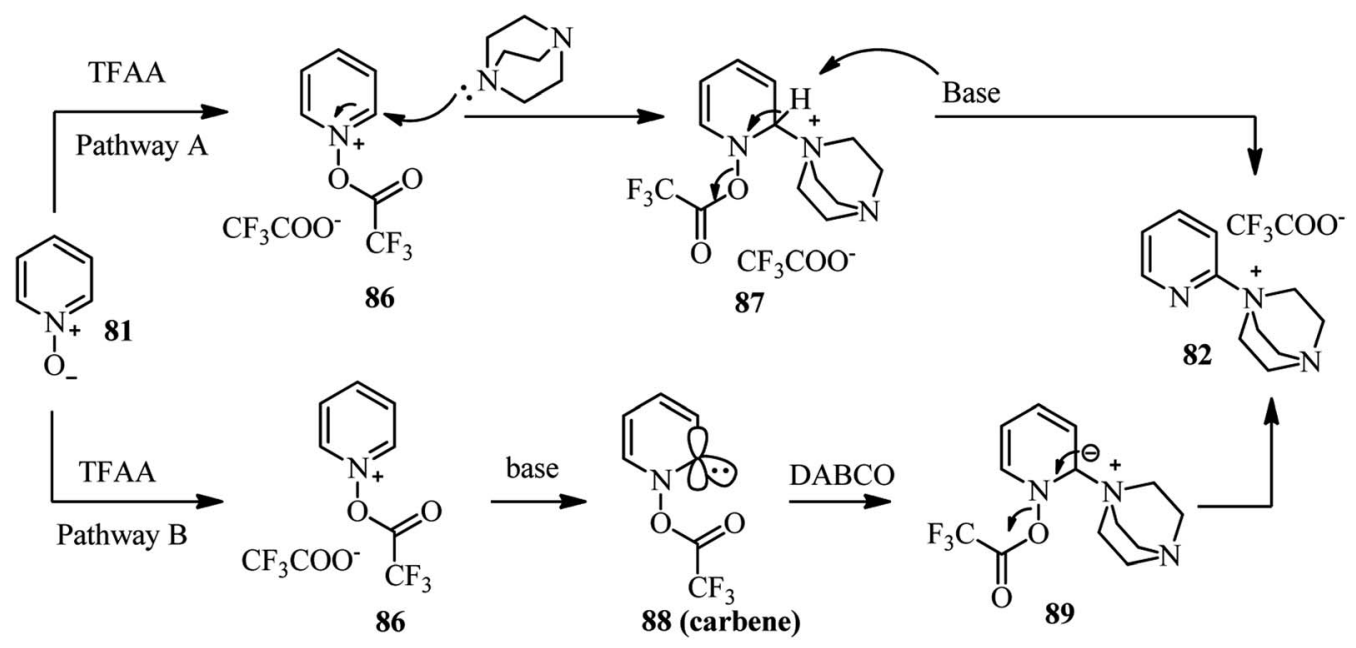

Scheme 32 Proposed mechanisms for the synthesis of $N$-(2-pyridyl)-DABCO salt from pyridine- $N$-oxide. 
1) $\mathrm{DABCO}$ (7 equiv),

TFAA (2.5 equiv),<smiles>[O-][n+]1cccc2ccccc21</smiles>

DMF, $0{ }^{\circ} \mathrm{C}$ to $\mathrm{rt}, 1 \mathrm{~h}$ and

rt to $90^{\circ} \mathrm{C}$ for $8 \mathrm{~h}$

2) $\mathrm{Nu}$ (4 equiv),

DMF, $90^{\circ} \mathrm{C}$, overnight

DABCO, TFAA, $0{ }^{\circ} \mathrm{C}$ to $\mathrm{rt}$

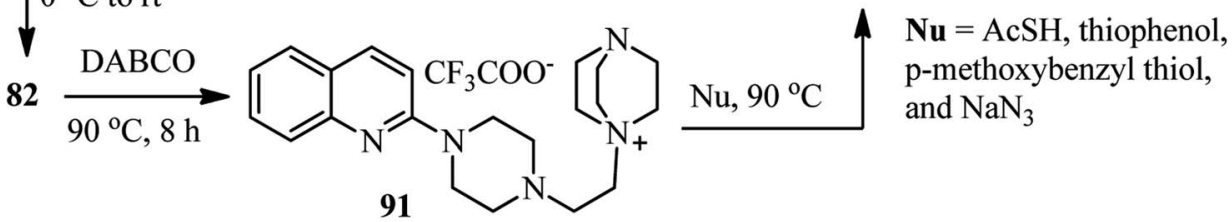

Scheme 33 Synthesis of quinolones containing bis(ethylpiperazine) motif.
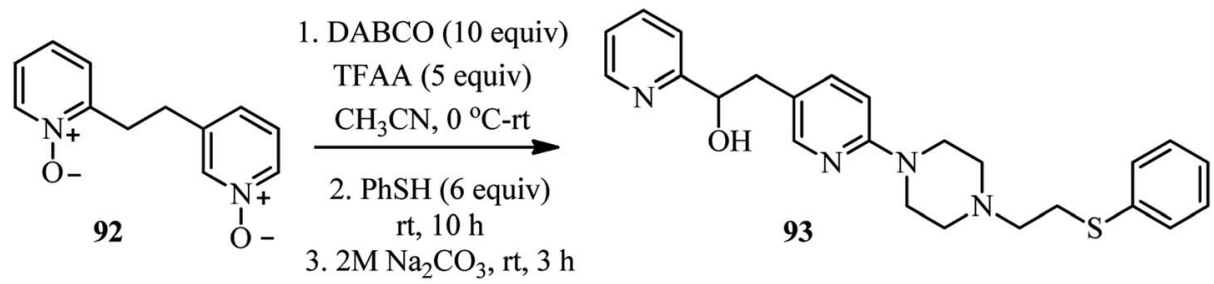

Scheme 34 Using bis-N-oxide in DABCO bond cleavage reaction.

complex heterocyclic compound 93 was obtained in $76 \%$ yield and complete regioselectivity (Scheme 34). They described that while the 3-alkylpyridine part reacted in the typical manner to produce a substituted piperazine, the 2-alkylpyridine fragment underwent the Boekelheide reaction, to afford the hydroxyl group after hydrolysis. ${ }^{44}$

\section{Diaryliodonium triflates as activating agents}

Recently, Karchava et al. introduced the diaryliodonium salts 94 as efficient arylating agents for a tertiary $\mathrm{sp}^{3}$-nitrogen. ${ }^{46}$ For this purpose, reaction of DABCO 1 (1 equiv.) with various aryl(mesityl)iodonium triflates 94 (2 equiv.) was carried out in

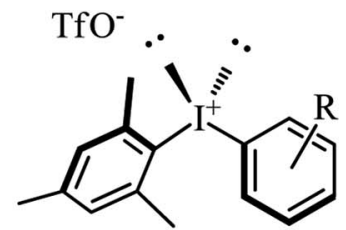

94

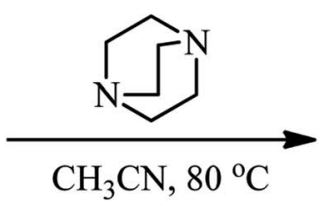

$16 \mathrm{~h}$

$\mathbf{R}=$ alkyl, halides, ethers, enolizable ketone, ester, primary and secondary amides, nitrile, trifluoromethyl, nitro, and etc

$\mathbf{N u}=$ Phthalimide, sulfonamide, azide, indole, imidazole, piperidine, carboxylic acids, phenols, thiophenols, sulfinates, diarylphosphine oxide, fluoride, nitrile, carbanion of malonitrile and esters<smiles>[R10]OCCN1CCN(c2cccc([R])c2)CC1</smiles>

$\mathrm{NuH}(\mathrm{Na}, \mathrm{K}$ or $\mathrm{Cs})$

DMF, $60{ }^{\circ} \mathrm{C}, 10 \mathrm{~h}$<smiles>[R]c1cccc(N2CCN(CC[NH])CC2)c1</smiles>

$\mathbf{5 5}(34-84 \%$ yields)

Scheme 35 Aryl(mesityl)iodonium triflates as activating agents for DABCO bond cleavage. 
<smiles>[R]c1cccc(N2CCN(CC(=O)OCc3ccco3)CC2)c1</smiles>

1 .<smiles>C=C(C)n1c(=O)[nH]c2ccccc21</smiles>
$80^{\circ} \mathrm{C}, 6 \mathrm{~h}$

2. $\mathrm{HCl}_{\mathrm{aq}}, i-\mathrm{PrOH}$

$70^{\circ} \mathrm{C}, 3 \mathrm{~h}$

$\mathrm{R}=\mathrm{CF}_{3}$<smiles>O=c1[nH]c2ccccc2n1CCN1CCN(c2cccc(C(F)(F)F)c2)CC1</smiles>

$$
\mathrm{R}=\mathrm{H} \mid \begin{gathered}
\text { 1. } \mathrm{BrCH}_{2} \mathrm{C}_{6} \mathrm{H}_{4} \mathrm{CN} \text { (1.1 equiv) } \\
\mathrm{MeCN}_{\text {, reflux, } 3 \mathrm{~h}}
\end{gathered}
$$

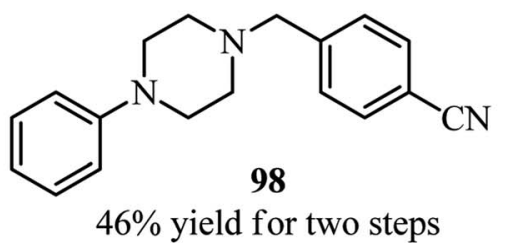

Scheme 36 Synthesis of biologically active compounds from $\mathrm{N}$-aryl-DABCO salts.

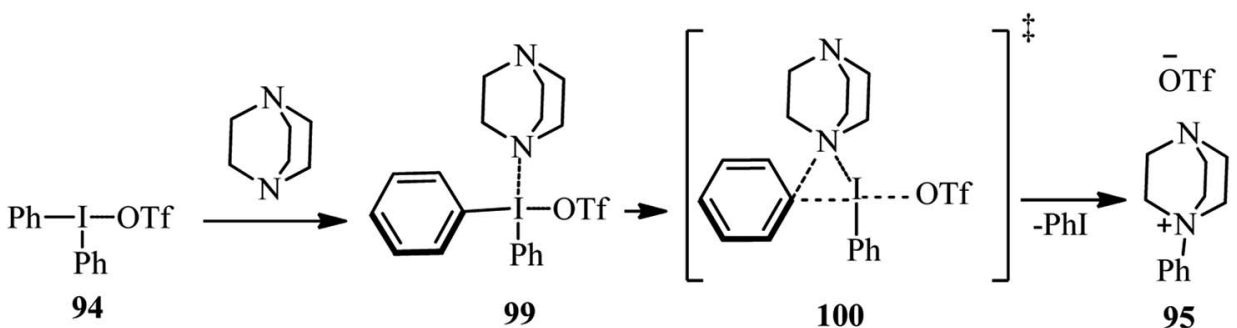

Scheme 37 Proposed mechanism for the reaction of DABCO with diaryliodonium triflate.

acetonitrile at $80{ }^{\circ} \mathrm{C}$ for $16 \mathrm{~h}$ to prepare the corresponding $N$ aryl-DABCO salts 95 with both electron-donating and electronwithdrawing groups in different positions of the aryl substituent in $42-96 \%$ isolated yields (Scheme 35). In continue, the reaction of salts 95 with various nucleophiles $\mathrm{NuH}$ (K, Na, Cs) including phthalimide, solfonamide, azide, indole-3carbaldehyde, imidazole, 4-benzylpiperidine, carboxylic acid salts, phenols, thiophenols, diphenylphosphine oxide, sodium benzenesulfinate, fluoride, cyanide, and malonitrile were performed in DMF at $60{ }^{\circ} \mathrm{C}$ for $10 \mathrm{~h}$ to afford the functionalized piperazines $\mathbf{5 5}$ as drug-like scaffolds, ligands, and synthetically useful compounds (Scheme 35). The synthetic usefulness of this protocol was examined for the synthesis of Flibanserin 97, the active agent of recently approved drug Addyi, in three steps starting from commercially available 1isopropenylbenzimidazol-2-one 96 and salt $95\left(\mathrm{R}=\mathrm{CF}_{3}\right)$. In addition, they have shown that the reaction of salt $\mathbf{9 5}$ with an alkylating agent like $p$-cyanobenzyl bromide, followed by treatment with $\mathrm{Na}_{2} \mathrm{~S}_{2} \mathrm{O}_{3}$ afforded the corresponding piperazines 98 in good yield (Scheme 36).

The authors proposed that the reaction of DABCO with diaryliodonium triflate $\mathbf{9 4}$ proceeds via an initial formation of $\mathbf{9 9}$, followed by a concerted ligand coupling at the iodine center to provide the salt $\mathbf{9 5}$. The structure of intermediate 99 was confirmed by X-ray analysis, in which the iodine center adapts a tetracoordinated planar arrangement with an $\mathrm{N} \cdots \mathrm{I}$ bond length of $2.848 \AA$ (Scheme 37).

\section{In situ prepared nitrile as activating agent}

A general method for introducing 4-(2-chloroethyl)piperazinyl group on the $\mathrm{C} 4$ position of 1,2,3-dithiazoles is developed by Koyioni et al. ${ }^{47}$ They concluded that reaction of $\mathrm{N}$-(4-chloro- $5 \mathrm{H}^{-}$ 1,2,3-dithiazol-5-ylidene)-anilines or 4-chloro-5 $\mathrm{H}-1,2,3-$ dithiazol-5-one (thione) 101 with DABCO in hot $\mathrm{PhCl}$ at $131{ }^{\circ} \mathrm{C}$ afforded the corresponding products 102 in high to excellent yields (Scheme 38). After successful synthesis of 102, their reaction with various nucleophiles such as $\mathrm{NaN}_{3}$, primary and secondary amines, potassium phthalimide, sodium acetate, sodium benzoate, potassium thiocyanate, thiols and potassium cyanide were carried out to give the appropriate products $\mathbf{1 0 3}$ with up to $97 \%$ isolated yields. While no reaction was occurred between DABCO and various (4-chloro-5 $\mathrm{H}$-1,2,3-dithiazol-5ylidene)methanes, the corresponding products 104 were 


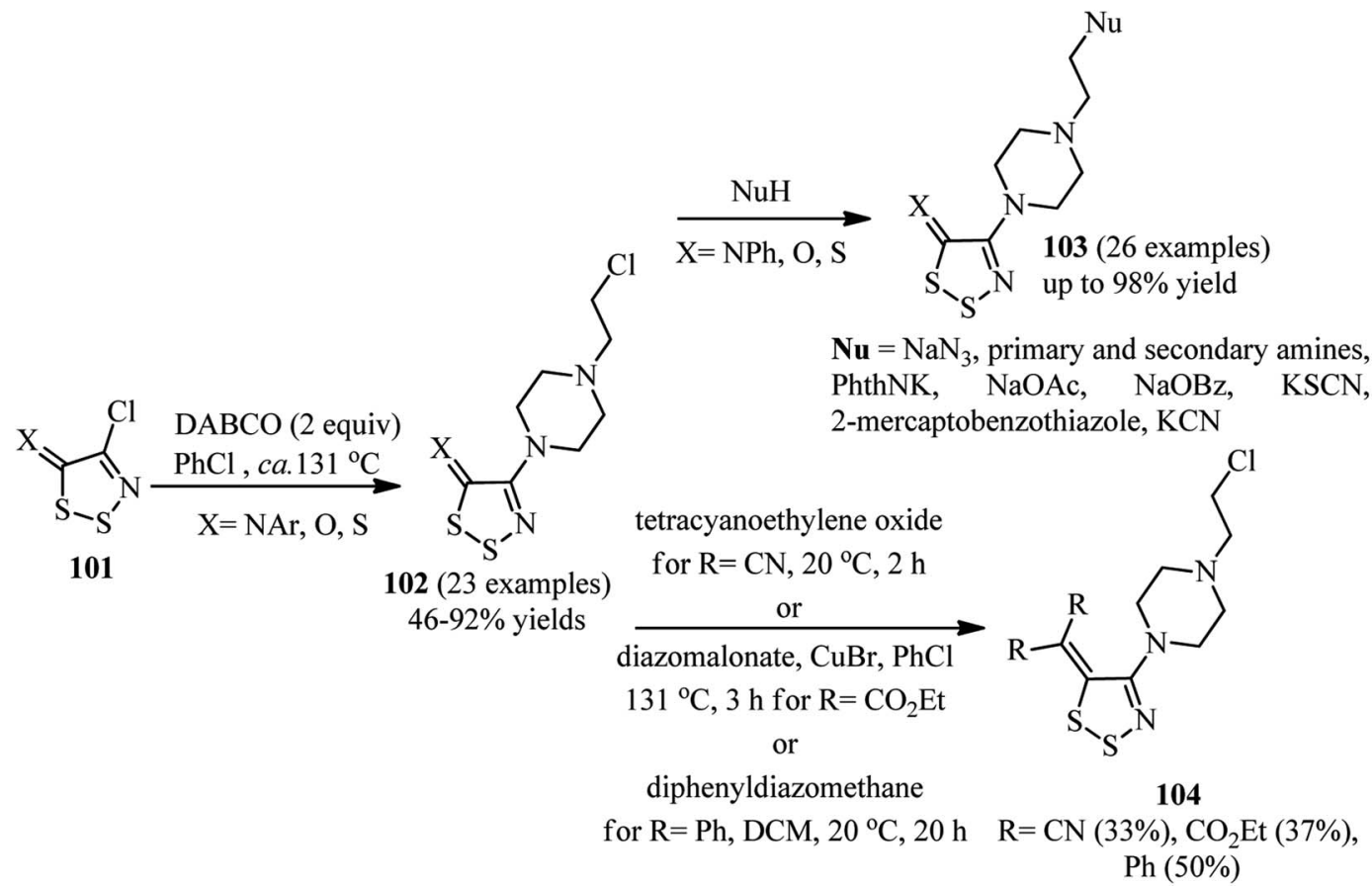

Scheme 38 Introducing 4-(2-chloroethyl)piperazinyl group on the C4 position of 1,2,3-dithiazoles and their postfuncionalization.

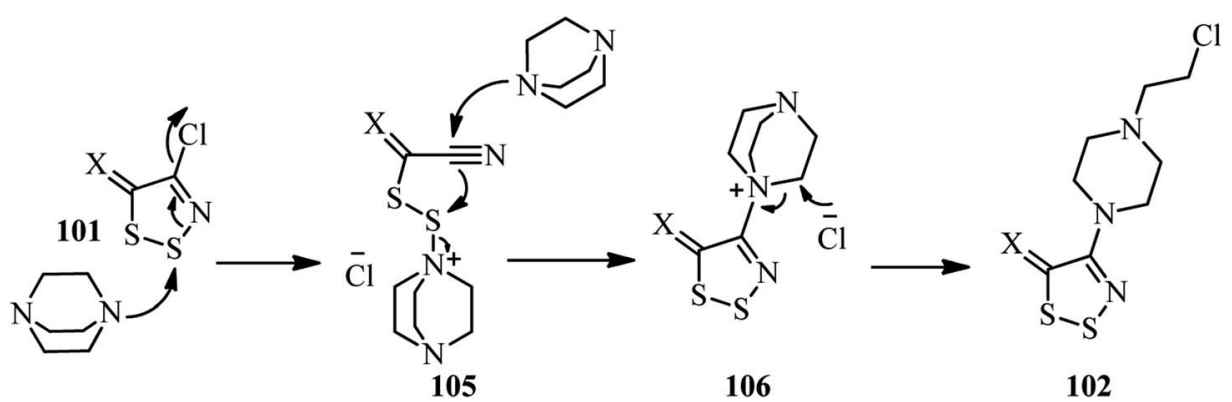

Scheme 39 Proposed mechanism for the reaction of 101 with DABCO.

obtained via the C5 postfunctionalization of the 4-(2-chloroethyl)piperazinyl dithiazolethione 102 in modest yields.

The authors proposed that the reaction proceeded via the ring-opening of the 1,2,3-dithiazole 101 by nucleophilic attack of DABCO on the sulfur $\mathrm{S} 2$ to afford the disulfide intermediate 105. Nucleophilic attack of the second molecule of DABCO to the nitrile group provided an amidine which then cyclizes onto the disulfide 106 to release the initial DABCO. Finally, the DABCO ring opening was occurred by chloride attack. In summary, the reaction proceeded via addition of nucleophile, ring-opening, and ring closure mechanism to prepared the corresponding DABCO salt (Scheme 39).

\section{Alkynes as activating agent}

Using alkynes as activator for DABCO ring opening is introduced by Dong and coworkers. They investigated the reaction of DABCO, a carboxylic acid, and an activated alkyne such as dimethyl acetylenedicarboxylate (DMAD) 107 under catalyst-free conditions in THF (Scheme 40). ${ }^{48}$ Various aromatic and aliphatic carboxylic acids were tolerated in this protocol. Not only DMAD, but also alkyl propiolates were examined as suitable substrates in this protocol. The role of DABCO is important in this protocol; while in the present of a catalytic amount of DABCO the main product is Michael addition of carboxylic acids to the alkynes, by using a stoichiometric amount of DABCO the corresponding piperazine adducts 108 were obtained in moderate to excellent yields. The configuration of the molecule around double bond was examines as $E$ by X-ray crystallography.

This protocol was applied for the synthesis of various (un) substituted amino carboxylic acid piperazine derivatives 110 by using amino acids instead of carboxylic acids. In the presence of amino acids, the products with $\operatorname{bis}(E)-1,2$-(dimethoxycarbonyl) ethen-1-yl moiety were obtained in high yields (Scheme 41). 


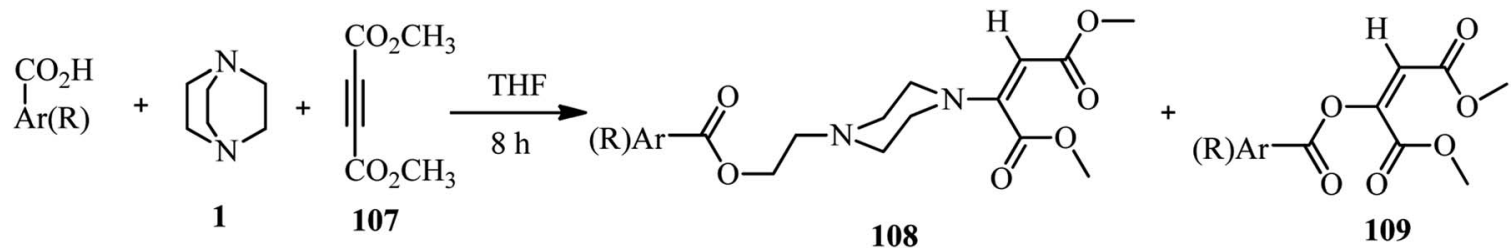

Scheme 40 One-pot three-component reaction of DABCO, DMAD and carboxylic acids.<smiles>[R]N([Y](=O)OCCN1CCN(C(C(=O)OC)=C(C(=O)OC)C(=O)OC)CC1)C(C(=O)OC)=C(C(=O)OC)C(=O)OC</smiles>

Aminoacids: p-aminobenzoic acid (69\%)

phenylalanine $(55 \%)$

proline $(78 \%$

Scheme 41 One-pot pseudo three-component reaction of DABCO, DMAD and amino acids.

\section{Sulfonyl chlorides as activating agents}

Although it is well documented that DABCO is an efficient substitute for pyridine in tosylation reactions and for triethylamine in sulfenylation reactions, but Hartung et al. have shown that by prolonging the reaction time in these reactions, the corresponding sulfonamide $\mathbf{1 1 2}$ can be isolated as side product via DABCO bond cleavage (Scheme 42). ${ }^{49}$

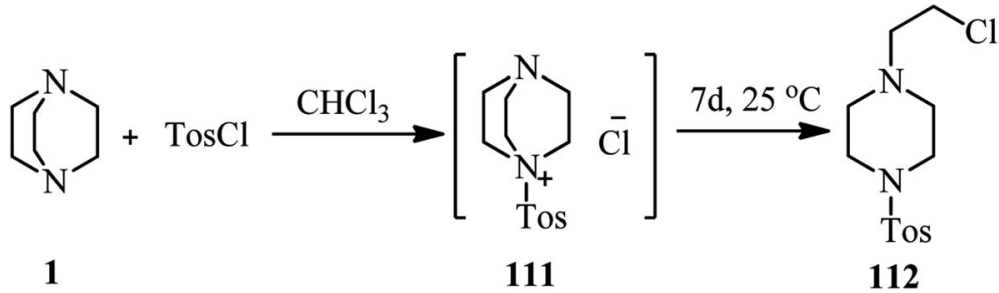

Scheme 42 Reaction of DABCO with tosyl chloride.

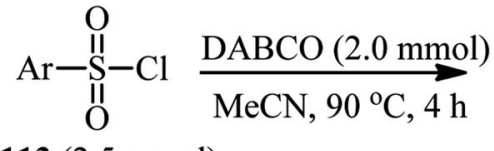

$113(2.5 \mathrm{mmol})$

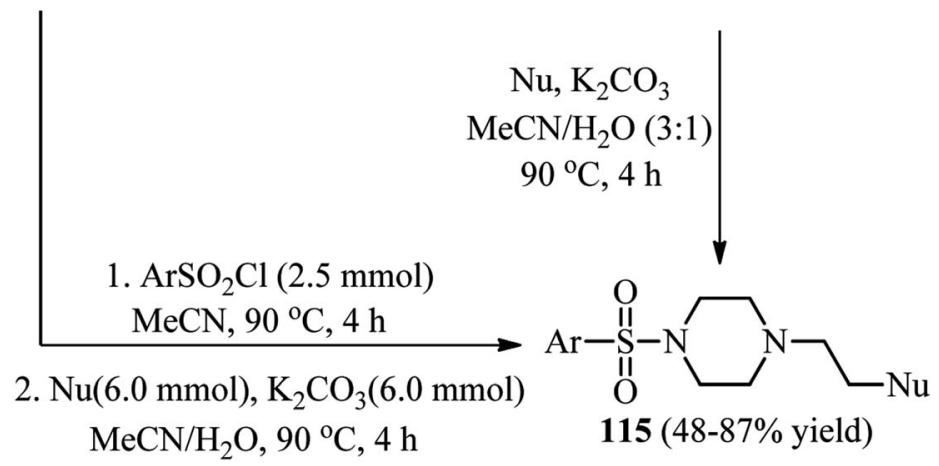

Scheme 43 A one-pot or two-pot strategy for the synthesis of 1-(2-substitued ethyl)-4-sulfonylpiperazines. 


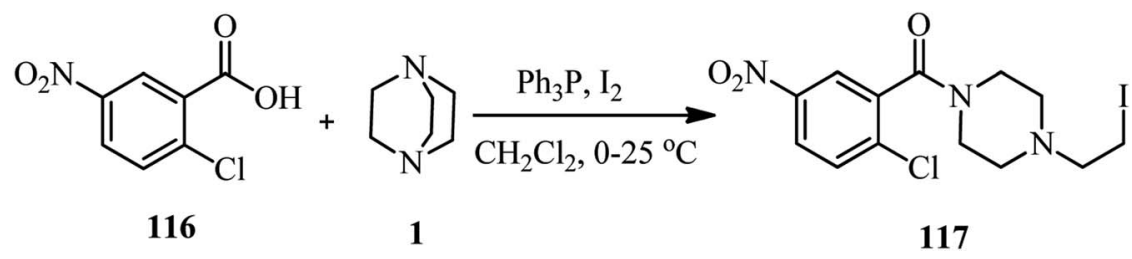

Scheme 44 Synthesis of piperazines via direct amidation of carboxylic acid with DABCO.

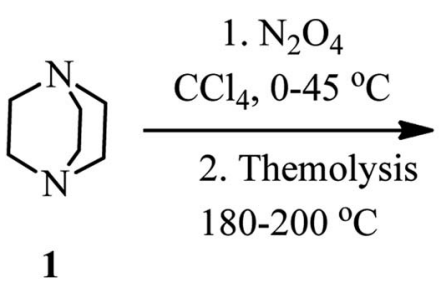

1. $\mathrm{N}_{2} \mathrm{O}_{4}$
This strategy has been further developed by Fu et al. for the synthesis of 1-(2-substitued ethyl)-4-sulfonylpiperazines $\mathbf{1 1 5}$ (50 $^{\mathbf{5}}$ They concluded that these compounds can be simply prepared via a two-step protocol by separation of the 1-(2-chloroethyl)-4sulfonylpiperazine intermediate $\mathbf{1 1 4}$ and then reaction with a nucleophile or via a one-pot two-step reaction of DABCO with a sulfonyl chloride, followed by addition of a nucleophile (Scheme 43). While aryl(heteroaryl) sulfonyl chlorides gave moderate to high yields, aliphatic sulfonyl chlorides do not participate in this protocol. Various nucleophiles including thiols, sodium methoxide, potassium thioacetate, potassium thiocyanate, secondary aromatic amines, carboxylic acids, phenols, and sodium benzene sulfinate were applied successfully in this protocol. According to the spectroscopic studies, the authors confirmed that the charge-transfer complex formation between sulfonyl chlorides and DABCO facilitates the $\mathrm{C}-\mathrm{N}$ bond cleavage of DABCO.

\section{Miscellaneous}

A metal-free direct amidation of carboxylic acid 116 with tertiary amines in the presence of $\mathrm{Ph}_{3} \mathrm{P}-\mathrm{I}_{2}$ is reported by Phakhodee et al. in 2016. They have shown that when DABCO was applied as a nitrogen source in the reaction with an acid, the DABCO ring underwent endocyclic $\mathrm{C}-\mathrm{N}$ bond cleavage to afford the iodo-substituted amide product 117 in $52 \%$ yield (Scheme 44$).{ }^{51}$

Reaction of DABCO with an excess amount of dinitrogen tetroxide in $\mathrm{CCl}_{4}$ at $0-40{ }^{\circ} \mathrm{C}$, followed by recrystalisation in ethanol and nitric acid afforded the corresponding diamine dinitrate in $74 \%$ isolated yield. Thermolysis of the diamine dinitrate salt at $180-200{ }^{\circ} \mathrm{C}$ gave the 1,4-dinitrosopiperazine 118 in low yield (Scheme 45). ${ }^{52}$

Enzyme-mediated oxidation of DABCO by $\mathrm{H}_{2} \mathrm{O}_{2}$ or ethylhydroperoxide (EHP) in the presence of chloride $\mathrm{Cl}^{-}$was published by Sayo et al. in 1988. They concluded that reaction of DABCO with chloroperoxidase (CPO)-EHP-Cl system at $\mathrm{pH}=5$ afforded the piperazine, dichloropiperazine (DCP), and formaldehyde as products. According to ESR experiments, they identified that the reaction proceeded via formation of DABCO chloroammonium cation, followed by homolysis of the cation (Scheme 46)..$^{53}$

Finally, a green and environmental benign procedure for the synthesis of functionalized 4-ethylpiperazines via a 3,4-dihalo2(5H)-furanone 119 initiated DABCO C-N bond cleavage under catalyst-free conditions is reported by $\mathrm{Wu}$ et $a .^{54}$ They have shown that reaction of DABCO with a 3,4-dihalo-2(5H)-furanone 119 in ethyl acetate at $95{ }^{\circ} \mathrm{C}$ under air atmosphere for $2 \mathrm{~h}$
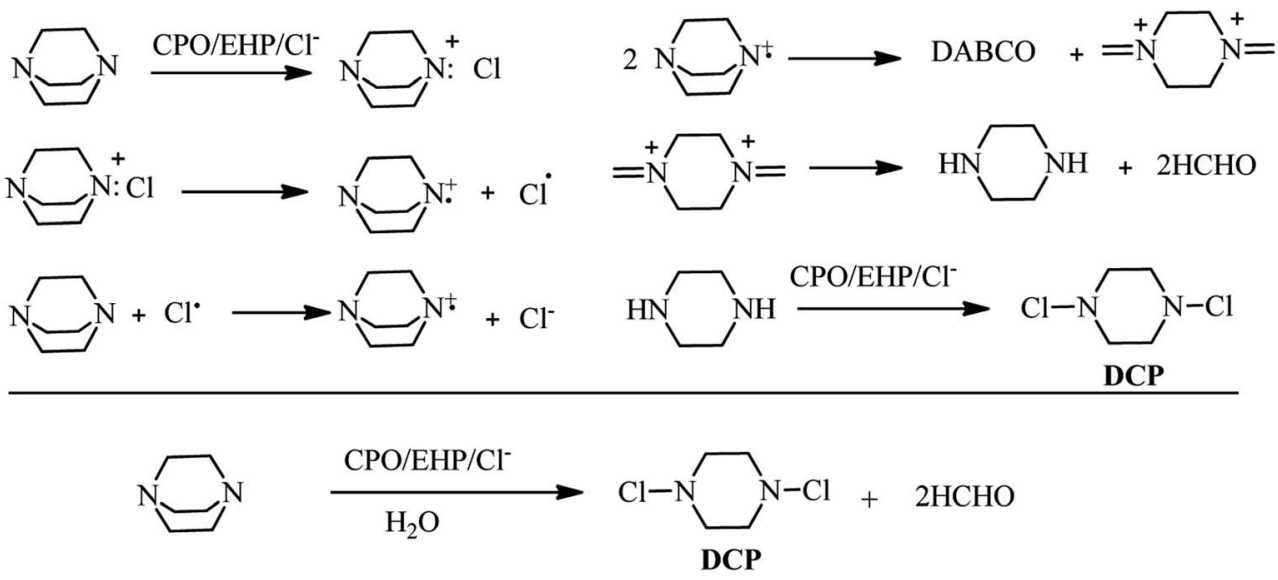

Scheme 46 Enzyme-mediated oxidation of DABCO by ethylhydroperoxide (EHP). 


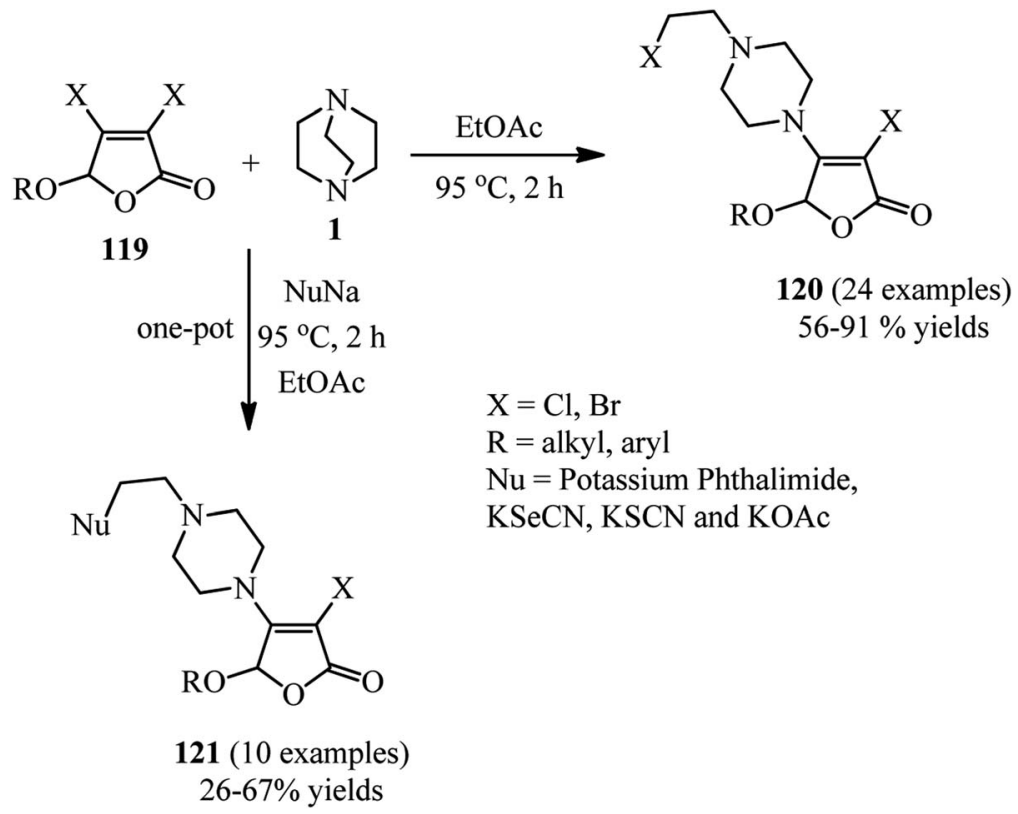

Scheme 47 Synthesis of piperazines using 3,4-dihalo-2(5H)-furanone.

afforded the corresponding furanone derivatives containing piperazine motif on the 4-position 120 in $56-91 \%$ yield with $100 \%$ atom economy (Scheme 47). Both 3,4-dibromo-2(5H)furanone and 3,4-dichloro-2(5H)-furanone are good substrates in this protocol. After successful synthesis of chloroethylpiperazine derivatives, displacement of the chloride in $\mathbf{1 2 0}$ with a nucleophile was carried out via a one-pot three-component reaction of DABCO, 119, and a nucleophile such as potassium salts of phthalimide, selenocyanate, and thiocyanate. The corresponding products 121 were obtained in $26-67 \%$ isolated yields.

\section{Conclusion}

Synthesis of functionalized piperazine derivatives via $\mathrm{C}-\mathrm{N}$ bond cleavage can be conveniently achieved using DABCO as the key substrate. Activation of DABCO with various reagents such as alkyl halides, aryl(heteroary) halides, carboxylic acids, diaryliodonium salts, tosyl halides, activated alkynes, benzynes and etc. provided the corresponding quaternary ammonium salts of DABCO, which are very good electrophiles for various nucleophiles for $\mathrm{C}-\mathrm{O}, \mathrm{C}-\mathrm{S}, \mathrm{C}-\mathrm{N}, \mathrm{C}-\mathrm{P}$ and $\mathrm{C}-\mathrm{C}$ bond formations. Besides pre-activated DABCO salts, the in situ activation of DABCO in multicomponent reactions were also applied for efficient synthesis of piperazine derivatives. The importance of functionalized piperazine derivatives in the development of novel drugs and biologically active compounds inspired the organic chemists to employ DABCO bond cleavage technique as a simple and efficient protocol in synthetic organic chemistry for the diversity oriented synthesis of these types of compounds. In this scenario, the dominance of DABCO bond cleavage technique in piperazines synthesis will definitely continue as long as our quest for novel functionalized piperazine derivatives continues.

\section{Conflicts of interest}

There are no conflicts to declare.

\section{Acknowledgements}

We are grateful to the research council of Kharazmi University for supporting this work (grant number 4/8575 and D/2056).

\section{References}

1 A. Gomtsyan, Chem. Heterocycl. Compd., 2012, 48, 7-10, DOI: 10.1007/s10593-012-0960-z.

2 M. Baumann and I. R. Baxendale, Beilstein J. Org. Chem., 2013, 9, 2265-2319, DOI: 10.3762/bjoc.9.265.

3 C. Cabrele and O. Reiser, J. Org. Chem., 2016, 81, 1010910125, DOI: 10.1021/acs.joc.6b02034.

4 E. Vitaku, D. T. Smith and J. T. Njardarson, J. Med. Chem., 2014, 57, 10257-10274, DOI: 10.1021/jm501100b.

5 (a) R. D. Taylor, M. MacCoss and A. D. G. Lawson, J. Med. Chem., 2014, 57, 5845-5859, DOI: 10.1021/jm4017625; (b) S. Verma and S. Kumar, Review Exploring Biological Potentials of Piperazines, Med. Chem., 2017, 7, 12-19, DOI: 10.4212/2161-0444.1000425.

6 N. Thanban Chandrika, S. K. Shrestha, H. X. Ngo, O. V. Tsodikov, K. C. Howard and S. Garneau-Tsodikova, J. Med. Chem., 2018, 61, 158-173, DOI: 10.1021/ acs.jmedchem.7b01138.

7 K. Pytka, A. Rapacz, M. Zygmunt, A. Olczyk, A. Waszkielewicz, J. Sapa and B. Filipek, Pharmacol. Rep., 2015, 67, 160-165, DOI: 10.1016/j.pharep.2014.08.016.

8 M. K. Parai, G. Panda, K. Srivastava and S. K. Puri, Bioorg. Med. Chem. Lett., 2008, 18, 776-781, DOI: 10.1016/ j.bmcl.2007.11.038. 
9 A. M. Brown, T. L. Patch and A. J. Kaumann, Br. J. Pharmacol., 1991, 104, 45-48, DOI: 10.1111/j.1476-5381.1991.tb12382.x.

10 G. Le Bihan, F. Rondu, A. Pele-Tounian, X. Wang, S. Lidy, E. Touboul, A. Lamouri, G. Dive, J. Huet, B. Pfeiffer, P. Renard, B. Guardiola-Lemaitre, D. Manechez, L. Penicaud, A. Ktorza and J. J. Godfroid, J. Med. Chem., 1999, 42, 1587-1603, DOI: 10.1021/jm981099b.

11 A. Ranise, A. Spallarossa, O. Bruno, S. Schenone, P. Fossa, G. Menozzi, F. Bondavalli, L. Mosti, A. Capuano, F. Mazzeo, G. Falcone and W. Filippelli, Farmaco, 2003, 58, 765-780, DOI: 10.1016/S0014-827X(03)00132-0.

12 (a) M. D. T. J. McNair, M. D. F. A. Wibin, E. T. Hoppe, M. D. J. L. Schmidt and M. D. F. A. dePeyster, J. Surg. Res., 1963, 3, 130-136, DOI: 10.1016/S0022-4804(63)80014-1; (b) C. S. A. Kumar, S. N. Swamy, N. R. Thimmegowda, S. B. B. Prasad, G. W. Yip and K. S. Rangappa, Med. Chem. Res., 2007, 16, 179-187, DOI: 10.1007/s00044-007-9022-y.

13 A. Ahmadi, M. Khalili, A. Nafarie, A. Yazdani and B. NahriNiknafs, Mini-Rev. Med. Chem., 2012, 12, 1282-1292, DOI: 10.2174/138955712802762013.

14 J. Guo, H. Tao, A. Alasadi, Q. Huang and S. Jin, Eat. Weight Disord., 2019, 24, 91-96, DOI: 10.1007/s40519-017-0424-7.

15 A. M. Waszkielewicz, M. Kubacka, K. Panczyk, S. Mogilski, A. Siwek, M. Glich-Lutwin, A. Grybos and B. Filipek, Bioorg. Med. Chem. Lett., 2016, 26, 5315-5321, DOI: 10.1016/ j.bmcl.2016.09.037.

16 V. F. Petrov and A. I. Pavluchenko, Mol. Cryst. Liq. Cryst., 2003, 393, 15-29, DOI: 10.1080/15421400390202890.

17 M. Zhang, C. Chen, Q. Wang, W. Fu, K. Huang and W. Zhou, J. Mater. Chem. A, 2017, 5, 349-354, DOI: 10.1039/ C6TA06037D.

18 (a) J. P. Safko, J. E. Kuperstock, S. M. McCullough, A. M. Noviello, X. B. Li, J. P. Killarney, C. Murphy, H. H. Patterson, C. A. Bayse and R. D. Pike, Dalton Trans., 2012, 41, 11663-11674, DOI: 10.1039/C2DT31241G; (b) C. Santini, M. Pellei, V. Gandin, M. Porchia, F. Tisato and C. Marzano, Chem. Rev., 2014, 114, 815-862, DOI: 10.1021/ cr400135x.

19 A. Chaudhari, A. Kuwar, P. Mahulikar, D. Hundiwale, R. Kulkarni and V. Gite, RSC Adv., 2014, 4, 17866-17872, DOI: $10.1039 /$ C4RA01880J.

20 S. Watson, M. Nie, L. Wang and K. Stokes, RSC Adv., 2015, 5, 89698-89730, DOI: 10.1039/C5RA17468F.

21 L. Yan, Y. Wang, J. Wei, G. Ji, H. Gu, Z. Li, J. Zhang, Q. Luo, Z. Wang, X. Liu, B. Xu, Z. Wei and C. Q. Ma, J. Mater. Chem. A, 2019, 7, 7099-7108.

22 H. Naarmann and H. Pohlemann, Ger. Offen., 1977, 19770518.

23 For recent review papers on the synthesis of piperazines: $(a)$ E. K. Gettys, Z. Ye and M. Dai, Synthesis, 2017, 49, 25892604, DOI: 10.1055/s-0036-1589491 and references are therein;; $(b)$ M. Al-Ghorbani, A. B. Bushra, M. S. V. Zabiulla and S. A. Khanum, Res. J. Pharm. Technol., 2015, 8, 611-628, DOI: 10.5958/0974-360X.2015.00100.6; (c) A. D. Borthwick, Chem. Rev., 2012, 112, 3641-3716, DOI: 10.1021/cr200398y; (d) Z. Ye, K. E. Gettys and M. Dai, Beilstein J. Org. Chem., 2016, 12, 702-715, DOI: 10.3762/bjoc.12.70;
D. I. Bugaenko, Chem. Heterocycl. Compd., 2017, 53, 12771279, DOI: 10.1007/s10593-018-2205-2.

24 H. K. Hall Jr, J. Org. Chem., 1963, 28, 1223-1224, DOI: 10.1021/jo01036a507.

25 V. I. Vysochin and G. V. Shishkin, Chem. Heterocycl. Compd., 1982, 18, 196-201, DOI: 10.1007/BF00512969.

26 N. Maras, S. Polanc and M. Kocevar, Org. Biomol. Chem., 2012, 10, 1300-1310, DOI: 10.1039/clob06676e.

27 M. Somei, S. Sayama, K. Naka, K. Shinmoto and F. Yamada, Heterocycles, 2007, 73, 537-554, DOI: 10.3987/COM-07-S(U) 31.

28 (a) S. D. Ross and M. Finkelstein, J. Am. Chem. Soc., 1963, 85, 2603-2607, DOI: 10.1021/ja00900a018; (b) S. D. Ross, J. J. Bruno and R. C. Petersen, J. Am. Chem. Soc., 1963, 85, 3999-4003, DOI: 10.1021/ja00907a020.

29 G. Lutze, H. Graubaum, M. Bartoszek, S. Griindemann and S. Flatau, J. Prakt. Chem., 1996, 338, 564-568, DOI: 10.1002/ prac.199633801106.

30 B. Kolesinska, K. Barszcz, Z. J. Kaminski, D. Drozdowska, J. Wietrzyk and M. Switalska, J. Enzyme Inhib. Med. Chem., 2012, 27, 619-627, DOI: 10.3109/14756366.2011.604482.

31 H. J. Wang, W. G. Earley, R. M. Lewis, R. R. Srivastava, A. J. Zych, D. M. Jenkins and D. J. Fairfax, Tetrahedron Lett., 2007, 48, 3043-3046, DOI: 10.1016/j.tetlet.2007.02.114.

32 H. J. Wang, Y. Wang, A. J. Csakai, W. G. Earley and R. J. Herr, J. Comb. Chem., 2009, 11, 355-363, DOI: 10.1021/cc8001662.

33 S. G. Gladstone, W. G. Earley, J. K. Acker and G. S. Martin, Tetrahedron Lett., 2009, 50, 3813-3816, DOI: 10.1016/ j.tetlet.2009.04.027.

34 Q. Zhu, Q. Yuan, M. Chen, M. Guo and H. Huang, Angew. Chem., Int. Ed., 2017, 56, 5101-5105, DOI: 10.1002/ anie. 201612017.

35 Q. Zhu, P. Yang, M. Chen, J. Hu and L. Yang, Synthesis, 2018, 50, 2587-2594, DOI: 10.1055/s-0036-1591577.

36 N. D. Reddy, A. J. Elias and A. Vij, J. Chem. Soc., Dalton Trans., 1999, 1515-1518, DOI: 10.1039/A809788G.

37 D. Vrantza, P. Kaloudis, L. Leondiadis, T. Gimisis, G. C. Vougioukalakis, M. Orfanopoulos, D. Gasparutto, J. Cadet, S. Encinas, C. Paris and M. A. Miranda, Helv. Chim. Acta, 2006, 89, 2371-2386, DOI: 10.1002/ hlca.200690220.

38 G. Min, J. Seo and H. M. Ko, J. Org. Chem., 2018, 83, 84178425, DOI: 10.1021 acs.joc.8b01058.

39 S. P. Ross and T. R. Hoye, Org. Lett., 2018, 20, 100-103, DOI: 10.1021/acs.orglett.7b03458.

40 S. P. Ross and T. R. Hoye, Nat. Chem., 2017, 9, 523-530, DOI: 10.1038/nchem.2732.

41 B. Boursalian, W. S. Ham, A. R. Mazzotti and T. Ritter, Nat. Chem., 2016, 8, 810-815, DOI: 10.1038/nchem.2529.

42 I. Yavari, M. J. Bayat and M. Ghazanfarpour-Darjani, Tetrahedron Lett., 2014, 55, 5595-5596, DOI: 10.1016/ j.tetlet.2014.08.045.

43 M. Ghazanfarpour-Darjani, F. Barat-Seftejani, M. Khalaj and S. M. Mousavi-Safavi, Helv. Chim. Acta, 2017, 100, e1700082, DOI: 10.1002/hlca.201700082.

44 D. I. Bugaenko, M. A. Yurovskaya and A. V. Karchava, J. Org. Chem., 2017, 82, 2136-2149, DOI: 10.1021/acs.joc.6b02952. 
45 L. Mosca, D. Rotili, I. Tempera, A. Masci, M. Fontana, R. Chiaraluce, P. Mastromarino, M. d'Erme and A. Mai, ChemMedChem, 2001, 6, 606-611, DOI: 10.1002/ cmdc.201000536.

46 D. I. Bugaenko, M. A. Yurovskaya and A. V. Karchava, Org. Lett., 2018, 20, 6389-6393, DOI: 10.1021/acs.orglett.8b02676.

47 M. Koyioni, M. Manoli and P. A. Koutentis, J. Org. Chem., 2016, 81, 615-631, DOI: 10.1021/acs.joc.5b02497.

48 H. R. Dong, Z. B. Chen, R. S. Li, H. S. Dong and Z. X. Xie, RSC Adv., 2015, 5, 10768-10772, DOI: 10.1039/C4RA14811H.

49 J. Hartung, S. Hunig, R. Kneuer, M. Schwarz and H. Wenner, Synthesis, 1997, 1433-1438, DOI: 10.1055/s-1997-1372.
50 Y. Fu, Q. S. Xu, Q. Z. Li, M. P. Li, C. Z. Shi and Z. Du, ChemistryOpen, 2019, 8, 127-131, DOI: 10.1002/ open.201800251.

51 W. Phakhodee, S. Wangngae and M. Pattarawarapan, RSC Adv. , 2016, 6, 60287-60290, DOI: 10.1039/C6RA12801G.

52 J. H. Boyer and T. P. Pillai, J. Chem. Soc., Perkin Trans. 1, 1985, 1661-1664, DOI: 10.1039/P19850001661.

53 H. Sayo, M. Hosokawa, E. Lee and K. Kariya, Chem. Pharm. Bull., 1988, 36, 2485-2489, DOI: 10.1248/cpb.36.2485.

54 H. Q. Wu, K. Yang, X. Y. Chen, M. Arulkumar, N. Wang, S. H. Chen and Z. Y. Wang, Green Chem., 2019, 21, 37823788, DOI: 10.1039/C9GC01740B. 